\title{
Systemic Risk: A New Trade-off for Monetary Policy?
}




\section{WP/15/142}

\section{IMF Working Paper}

\section{Systemic Risk: A New Trade-off for Monetary Policy?}

by Stefan Laseen, Andrea Pescatori, and Jarkko Turunen

IMF Working Papers describe research in progress by the author(s) and are published to elicit comments and to encourage debate. The views expressed in IMF Working Papers are those of the author(s) and do not necessarily represent the views of the IMF, its Executive Board, or IMF management.
I N T E R N A T I O N A L
$M O N E T A R Y$
F U N D 


\title{
IMF Working Paper
}

Western Hemisphere Department

Systemic Risk: A New Trade-off for Monetary Policy?

Prepared by Stefan Laseen, Andrea Pescatori, and Jarkko Turunen ${ }^{1}$

Authorized for distribution by Nigel Chalk

June 2015

IMF Working Papers describe research in progress by the author(s) and are published to elicit comments and to encourage debate. The views expressed in IMF Working Papers are those of the author(s) and do not necessarily represent the views of the IMF, its Executive Board, or IMF management.

\begin{abstract}
We introduce time-varying systemic risk in an otherwise standard New-Keynesian model to study whether a simple leaning-against-the-wind policy can reduce systemic risk and improve welfare. We find that an unexpected increase in policy rates reduces output, inflation, and asset prices without fundamentally mitigating financial risks. We also find that while a systematic monetary policy reaction can improve welfare, it is too simplistic: (1) it is highly sensitive to parameters of the model and (2) is detrimental in the presence of falling asset prices. Macroprudential policy, similar to a countercyclical capital requirement, is more robust and leads to higher welfare gains.
\end{abstract}

JEL Classification Numbers: E3, E52, E58, E44, E61, G2, G12

Keywords: Monetary Policy, Endogenous Financial Risk, DSGE models, Non-Linear Dynamics, Policy Evaluation

Author's E-Mail Address: SLaseen@imf.org, APescatori@imf.org, JTurunen@imf.org

${ }^{1}$ We are grateful for helpful comments from and discussions with Giovanni Dell'Ariccia, Ravi Balakrishnan, Vikram Haksar, Tommaso Mancini-Griffoli, Pau Rabanal, Damiano Sandri, Lars Svensson, and Edouard Vidon and to Raf Wouters for generously sharing his code. 


\section{Non-Technical Summary}

The global financial crisis (GFC) has challenged the pre-crisis "benign neglect" view among many central banks that using interest rate policy to counteract financial sector exuberance, such as asset price bubbles, is too imprecise, too costly and likely to be ineffective. We contribute to an emerging literature that attempts to build on the lessons from the GFC to re-evaluate this view.

We introduce time-varying systemic risk in an otherwise standard New-Keynesian general equilibrium model to study whether a simple leaning-against-the-wind policy can reduce systemic risk and improve welfare. Our framework captures the non-linear behavior of financial variables and their interaction with the real economy. Specifically, following $\mathrm{He}$ and Krishnamurthy (2014) and Dewachter and Wouters (2014) we include two financial frictions:

- While financial intermediaries (which include both banks and non-banks) are owned by households, they are operated by managers who maximize the return on intermediaries' equity. This friction results in pro-cyclical risk-taking behavior in the financial sector.

- It is difficult to raise funds during periods of financial stress. This friction introduces an asymmetry: in bad times a fall in asset prices that lowers the return on equity makes it difficult to raise funds, whereas no such equity constraint exists in good times.

Taken together these frictions and their interaction with the real economy generate systemic risks: a fall in asset prices that induces a sufficiently large decline in the return on financial intermediaries' equity renders them unable to raise equity. As a result, their portfolio becomes riskier, prompting risk averse managers to require higher risk-adjusted returns in the future (the Sharpe ratio increases). To deliver the higher expected returns the price of capital must decline. Lower asset prices propagate the financial stress to the real economy by reducing the volume of investment in physical capital which results in a further deterioration in the macroeconomic environment, raising the possibility of a vicious cycle.

We calibrate the model to approximate observed macroeconomic and financial sector data. Extending He and Krishnamurty (2014) and following Adrian and Shin (2013), we assume that financial intermediaries expand their balance sheet by borrowing. As a result, financial sector leverage and asset prices move in the same direction over the business cycle.

We use the model as a laboratory to analyze the effects of simple monetary policy rules that include leverage on financial variables, systematic risk and, more generally, welfare. We limit our analysis to simple policy rules to proxy a monetary policy behavior which could be, in principle, sufficiently predictable and learnable in a more general context. This also leads us to focus our analysis on observable measures of systemic risk such as 
leverage. We compare results from using simple policy rules to results from using countercyclical macro-prudential policy to lean against leverage.

Our main findings can be summarized as follows:

- We find that an unexpected increase in policy rates reduces output, inflation, and asset prices without fundamentally mitigating financial risks.

- However, a systematic monetary policy that progressively reacts to financial risks can improve welfare. The private sector responds to the expectation of a policy response by taking fewer risks. For example, a simple (Taylor type) policy rule that incorporates financial sector leverage can improve welfare by sacrificing a modest amount of growth today in order to significantly reduce the risk of economically costly financial crises in the future.

- While a systematic monetary policy reaction based on a simple policy rule that leans against leverage can improve welfare, we find that it is too simplistic. First, the benefits from leaning against leverage are is sensitive to parameters of the model, such as the degree to which financial sector leverage is pro or counter-cyclical. Second, leaning against leverage is detrimental in the presence of falling asset prices, potentially exacerbating incipient financial stress.

- In comparison, macroprudential policy, similar to a countercyclical capital requirement, is more robust and leads to significantly higher welfare gains, largely because, unlike policy rates, it is unburdened with trying to also achieve inflation and output objectives at the same time.

In sum, we find that in theory, systematic monetary policy can be used to reduce systemic financial stability risks if other, more targeted policy options (such as macroprudential policies) are a not available. However, practical implementation is faced with substantial challenges that are largely outside the scope of this study. For example, policymakers may find it difficult to systematically identify and measure rising financial excesses in a timely manner. 


\section{Introduction}

Prior to the great financial crisis the mainstream view held among central banks was that using interest rate policy to counteract financial exuberance (such as asset price bubbles) was costly or ineffective (Bernanke and Gertler [7], Gilchrist and Leahy [22], Greenspan [24]). ${ }^{1}$ The global financial crisis (GFC), however, has put this "benign neglect" approach into question, bringing the issue of whether monetary policy should explicitly include financial stability as an independent objective and use (some) specific financial variables as intermediate targets to the forefront of the policy debate (Borio [9]). There is now, indeed, the widely held belief that the current financial architecture is inherently fragile and that widespread externalities - stemming from some form of asset price corrections - can have a systemic impact on the financial sector, disrupting financial intermediation and, in turn, jeopardizing the normal functioning of the real economy (Adrian et al $[2])$.

We re-assess the optimal monetary policy conduct when the financial intermediation sector can be subject to disruptions which would then trigger adverse effects for the real economy. These systemwide financial disruptions are rare but highly damaging. To capture them appropriately we use a framework that accommodates potentially highly non-linear behavior of financial variables and their two-way interaction with the real economy. As a result, it is important to assess monetary policy in a model in which financial constraints on the intermediary sector only bind in some "bad" states. More specifically, we introduce time-varying systemic risk in an otherwise standard New-Keynesian model that can approximate data for macroeconomic and financial variables. In particular, following He and Krishnamurthy [28] we include two financial frictions: 1) there is a separation between ownership and management of financial intermediaries which induces a excessively pro-cyclical risk-taking behavior of the financial sector; 2) there is an equity constraint which makes it difficult for financial intermediaries to raise funds during periods of financial stress. This occasionally binding constraint introduce a substantial asymmetry between good and bad times. Bad states can morph into a financial crisis due to a negative feedback loop effect: an initial drop in asset prices that induces a sufficient fall in the return on equity of the financial sector to make the equity constraint bind; the difficulty of raising equity implies, in turn, that the intermediary sector will bear more risk in its portfolio and the Sharpe ratio will rise - analog to a rise in risk

\footnotetext{
${ }^{1}$ Moreover, the additional information brought about by financial variables relatively to the one already incorporated in inflation and output gap was considered minimal and occasional financial disruptions could be dealt with by following the traditional lender-of-last-resort function (Bagehot [5]).
}

CInternational Monetary Fund. Not for Redistribution 
aversion. A higher Sharpe ratio on capital investment, in turn, implies that the price of capital must be lower in order to deliver the higher expected returns. Lower asset prices propagates the financial stress to the real economy by reducing the volume of investment in physical capital which in turn deteriorate further the macroeconomic environment and raise the probability of a vicious cycle.

Extending He and Krishnamurthy [28] and following Adrian and Shin [1], our baseline calibration assumes that financial intermediaries expand their balance sheet by borrowing rather than raising equity, which results in a positive co-movement between leverage and asset prices. ${ }^{2}$ Empirical evidence suggests that financial sector leverage is indeed pro-cyclical, although results vary across sectors and over time. For example, using pre-crisis aggregate financial accounts data, Adrian and Shin [1] find that leverage increases with total assets for broker-dealers. This result is confirmed by Nuno and Thomas [33], who extend data up to 2011 and find evidence that leverage is procyclical for both broker dealers and for commercial banks. Finally, Kalemli-Ozcan et al. [29] use pre-crisis microdata and find that leverage is procyclical for investment banks and for large commercial banks; similar to Greenlaw et al. [23] (who look at a few individual banks). Our model is rich enough to qualitatively replicate the cross-correlation between leverage and output found in the data. Specifically, leverage lags output and is more persistent over the business cycle. ${ }^{3}$

Finally, we use a third order solution method to account for changes in risk premia and tail events which contribute to the financial intermediaries' choices about leverage and risk taking, and the vulnerability of the financial sector. Capturing non-linear behavior of macroeconomic variables in periods of financial stress is crucial to properly evaluating the welfare costs related to systemic risk.

We use our model as a laboratory to analyze the effect of simple monetary policy rules on the stochastic properties of financial variables, systematic risk and, more generally, welfare. We limit our analysis to simple rules to proxy a monetary policy behavior which could be, in principle, sufficiently predictable and learnable in a more general context-i.e., we proxy a central bank operating in a framework that is consistent with the general principles of a flexible inflation targeting

\footnotetext{
${ }^{2}$ See BIS [6] for a detailed survey of alternative transmission channels between the financial and the real sectors. Risk taking in our framework occurs on the liability side of banks. Another interesting margin of risk taking is asset quality. For an example of a DSGE model with a search-for-yield among banks see Cociuba, Shukayev and Ueberfeldt $[15]$.

${ }^{3}$ Some commentators have noted that the asynchronicity of business cycle fluctuations and the financial cycle (defined as fluctuations in some chosen financial variables) poses a challenge to monetary policy (see Borio [9]).
} 
framework. This leads us to focus our analysis on observable measures of systemic risk such as leverage. As a benchmark we also compare the optimal interest rate policy result against a simple targeted macroprudential rule where a time-varying tax (subsidy) is levied on financial intermediaries according to leverage being above (below) its unconditional mean.

The findings of our analysis can be summarized as follows:

A monetary policy tightening surprise does not necessarily reduce systemic risk, particularly when the state of the financial sector is fragile. The negative impact of the surprise tightening on output, inflation, asset prices, and the rise of funding costs for financial intermediaries implies a reduction in profitability of the financial sector without altering their risk taking behavior. The negative effects of a monetary policy surprise are mitigated when the financial sector is strong and the surprise is small.

Risk taking behavior is affected by systematic monetary policy reaction. Systematic policy based on a simple (Taylor type) policy rule that includes financial variables such as leverage, can improve welfare by striking a balance between inflation and output stabilization on the one hand and reducing the likelihood of financial stress on the other. A simple policy reaction to leverage, however, is not robust and is too simplistic. First, leaning against the wind requires financial sector leverage to be pro-cyclical. As discussed above, empirical evidence is mixed and suggests that procyclicality varies across sectors and over time. Second, even if leverage is pro-cyclical, when leverage increases because of a sharp fall in asset prices, an increase in policy interest rates exacerbates the initial asset price correction. Leaning against leverage without clearly distinguishing why leverage is increasing could therefore lead to a policy mistake that exacerbates incipient financial stress, possibly inducing a full blown crisis. Alternative financial variables such as measures of mis-pricing of risk have more appealing properties since risk aversion (i.e., asset price undervaluation) always increases in crisis times. However, they are not directly observable and less affected by monetary policy, leading to only modest welfare improvements. A simple macroprudential rule which acts similarly to a counter-cyclical capital requirement (making it more costly to raise debt during good times and vice versa) is substantially better than the interest policy rule in limiting the buildup of leverage and preventing crisis.

Finally, an excessive stabilization of output leads to a compression of risk premia, higher asset prices, investment levels, and, thus, leverage (which is necessary to finance the higher investment levels). When the financial system faces sharper negative shocks, however, the higher leverage becomes a vulnerability leading to sharper downturns. This feature is analog to the volatility 
paradox described in Brunnermeier and Sannikov [10]. ${ }^{4}$ In this context, a monetary policy reaction to output over and above the one warranted in the absence of financial frictions leads to lower welfare.

In relation to the literature most existing studies have found little or no welfare benefit from monetary policy targeting (or "leanings against") financial variables. ${ }^{5}$ However, differently from ours, these studies are subject to several limitations: credit frictions affect only non-financial borrowers (as in models a la Kiyotaki and Moore [31], Carlstrom and Fuerst [11], Carlstrom, Fuerst, and Paustian [12] or Bernanke and Gertler and Gilchrist [8]); asset price deviations from fundamentals or, more generally, financial shocks are assumed to be exogenous; and the solution techniques that have been used remove non-linear dynamics which are crucial for describing the impact of crisis and to accurately assess welfare implications (e.g., Woodford [42]). A notable exception is Brunnermeier and Sannikov [10] who put financial frictions at the center of the monetary policy transmission mechanism. However, given that financial frictions are the only source of inefficiencies in their model, the trade-off with traditional monetary policy goals such as inflation and output gap stabilization is removed by assumption. Finally, some analyses (such as Svensson [39] and Ajello et al [3]), focus on the effect of a monetary policy surprises on systemic risk finding little or negligible welfare gains. In the present paper, instead, we will place more emphasis on how a systematic monetary policy reaction to financial variables, which is fully internalized by private agents, can affect welfare, while broadly confirming the results of Svensson [39] and Ajello et al [3] in relation to a surprise policy tightening. ${ }^{6}$

The rest of the paper is organized as follows. We present the model in section II and calibrate the model and describe how the model matches the data for key macro and financial variables in section III. We discuss model properties and perform welfare analysis for alternative policy rules in section IV before concluding with a summary of our results in section $\mathrm{V}$

\footnotetext{
${ }^{4}$ The volatility paradox can be described by the following passage: "Paradoxically, lower exogenous risk can lead to more extreme volatility spikes in the crisis regime. This happens because low fundamental risk leads to higher equilibrium leverage." (Brunnermeier and Sannikov [10])

${ }^{5}$ In addition to Bernanke and Gertler [7], papers that have found small or no welfare benefits from leaning-against financial variables include Ajello et al [3], Angeloni and Faia [4], Faia and Monacelli [19], De Groot [16], Quint and Rabanal [34], and Svensson [39].

${ }^{6}$ It is also important to note that as opposed to Svensson [39] and Ajello et al [3] the severity of financial stress and its welfare implications are endogenous in our setup.
} 


\section{The Model}

The specification of the macroeconomic block of the model follows standard New-Keynesian DSGE models (Christiano et al., [14]; Smets and Wouters, [37]) whereas the financial sector is modeled as in He and Krishnamurthy [28]. Time is discrete and indexed by $t$. The economy has three sectors: households, financial intermediation, and goods production. We assume that the capital stock is owned by financial intermediaries which are run by a manager. We interpret the intermediaries to include both commercial banks, as well as non-banks (such as investment banks, hedge funds and private equity funds).

\subsection{Household Sector}

A representative household maximizes the expected utility flow:

$$
U_{t}=E_{0} \sum_{t=0}^{\infty} \beta^{t} u\left(C_{t}, L_{t}\right)
$$

where $\beta$ is the discount factor and $C_{t}$ and $L_{t}$ denotes consumption and labor effort respectively. The instantaneous utility function is specified as in Greenwood et. al. [25], eliminating the wealth effect on labor supply

$$
u\left(C_{t}, L_{t}\right)=\frac{\left(C_{t}-h C_{t-1}-\psi L_{t}^{1+\phi_{L}} /\left(1+\phi_{L}\right)\right)^{1-\sigma}-1}{1-\sigma},
$$

where $\sigma$ the inverse of inter-temporal elasticity of substitution, $1 / \phi_{L}$ is the Frisch elasticity of labor supply. The parameter $\psi>0$ is used for accounting for the steady state of $L_{t}$, while $h$ captures external habit formation on consumption.

Households maximize their objective function subject to an intertemporal budget constraint which is given by: ${ }^{7}$

$$
W_{t}=w_{t}^{n} L_{t}-P_{t} C_{t}+\tilde{R} V_{t-1}+R_{t-1}^{f} B_{t-1}+D_{t}^{k}-0.5 \phi_{c w} \pi_{w, t}^{2} \bar{Y}
$$

where $W_{t}$ is financial wealth and $w_{t}=w_{t}^{n} / P_{t}$ is the real wage expressed in terms of final consumption, $P_{t}$ is the price of the final consumption bundle while the last term represents nominal wage adjustment costs. Households are assumed to not be able to directly own the capital stock - even though they own capital producers which rebate their profits $D_{t}^{k}$ to households. Instead, households invest their wealth in risky and risk-free assets issued directly by the financial sector. More

\footnotetext{
${ }^{7}$ The budget constraint can also be written as $W_{t}=P_{t}\left(w_{t} L_{t}-C_{t}\right)+R_{t}^{w} W_{t-1}+D_{t}^{k}$, where $R_{t}^{w}=\left[R_{t}^{f}\left(1-\alpha_{t-1}\right)+\right.$ $\left.\tilde{R}_{t} \alpha_{t-1}\right]$ is a weighted average of the risk-free and risky return with weight $\alpha_{t-1}=V_{t} / W_{t}$.
} 
precisely, a minimum fraction of household wealth $\lambda$ is channeled into risk-free deposits, $B_{t}$, for transaction and liquidity services that earn a gross real return $R_{t-1}^{f}=\left(1+i_{t-1}\right)$-where $i_{t-1}$ is the nominal risk-free rate. The real risk-free rate governs the consumption-saving choice of the households through a standard Euler equation: ${ }^{8}$

$$
\beta E_{t} \frac{u_{c, t+1}}{u_{c, t}} \frac{1+i_{t}}{1+\pi_{t+1}}=1
$$

where $\pi_{t}$ is the inflation rate of consumption prices $P_{t}$ while the marginal utility of consumption is given by $u_{c, t}=\left[C_{t}-h C_{t-1}-\psi L_{t}^{1+\phi_{L}} /\left(1+\phi_{L}\right)\right]^{-\sigma}$.

The other fraction $1-\lambda$ is invested either in risky financial assets $V_{t}$ which earn a stochastic return $\tilde{R}_{t}$, or in deposits. Both returns are taken as given. The portfolio choice of investing in risky financial liabilities of a financial intermediary depends on the "reputation", $e_{t}$, acquired by the financial intermediary. We assume that for each intermediary the following relation holds (where $\bar{W}$ is steady state wealth $)^{9}$

$$
V_{t}=\min \left\{e_{t-1},(1-\lambda) \bar{W}^{\gamma} W_{t}^{1-\gamma}\right\}
$$

When $\gamma=1$, during good times the share of household wealth invested in risky asset is constant, $\alpha_{t} \equiv V_{t} / W_{t}=1-\lambda$. In bad times, however, when the financial sector is perceived fragile the equity share $\alpha_{t}$ falls with $e_{t}$. As we will see, choosing $\gamma=1$ is consistent with the empirical observation that financial sector leverage is procyclical.

Finally, we describe wage setting and labor supply. The marginal rate of substitution between consumption and leisure is given by the ratios of marginal utilities

$$
m r s_{t}=\psi L_{t}^{\phi_{L}}
$$

Following the New-Keynesian tradition, we assume the households have market power in setting their nominal wages such that the nominal wage expressed in final consumption goods price is a markup over the household marginal rate of substitution

$$
w_{t}^{n}=\mu_{w, t} m r s_{t}
$$

\footnotetext{
${ }^{8}$ The real risk-free rate can be defined implicitly as $R_{t}^{r}=1 /\left[\beta E_{t} \frac{u_{c, t+1}}{u_{c, t}}\right]$.

${ }^{9}$ The household portfolio allocation between risky and safe assets is price insensitive. Implicitly, we are assuming that there are limits to arbitrage and deposits and intermediary equity are not close substitute. Hence, there is no direct arbitrage equation linking the return on equity and the return on risk-less deposits. As we will see, asset prices (the price of physical capital) equilibrate demand and supply of risky funds to the financial sector. The consumption-saving choice, however, is still captured by the Euler equation on bonds
} 
while evolution of the wage markup $\mu_{w, t}$ is determined by nominal rigidities in setting wages such that the following wage Phillips curve governs wage inflation $\pi_{w, t}=\pi_{t} w_{t} / w_{t-1}$

$$
\pi_{w, t}=\left(1-\gamma_{w}\right) E_{t} \pi_{w, t+1}+\gamma_{w} \pi_{w, t-1}-\kappa_{w}\left(\mu_{w, t}-\mu_{s s}\right)
$$

The cost of wage inflation is born by the household and amounts to a loss of resources equal to $0.5 \phi_{c w} \pi_{w, t}^{2} \bar{Y}$. The parameter $\phi_{c w}$ is a function of $\kappa_{w}$ such that in a first order approximation adjustment costs a la Rotemberg and Calvo would give the same dynamics (see Lombardo and Vestin [32]).

\subsection{Real Sector (Production)}

Following the New-Keynesian framework, there is a continuum of monopolist firms that produce differentiated goods according to the technology

$$
Y_{t}=A_{t} L_{t}^{\alpha} K_{t-1}^{1-\alpha}-\Phi \bar{Y}
$$

where the demand for individual firm's output is given by $y_{t}^{*}=\left(p_{t}^{*} / P_{t}\right)^{-\epsilon} Y_{t}$. The law of motion for physical capital is given by

$$
K_{t}=(1-\delta) K_{t-1}+I_{t}
$$

however, since firms are owned by intermediaries the investment decision, $I_{t}$, is actually driven by financial intermediaries (see next section).

The labor demand is given by

$$
w_{t}=m c_{t} \alpha A_{t} L_{t}^{\alpha-1} K_{t}^{1-\alpha}
$$

Firms face price adjustment costs a la Rotemberg, governed by the parameter $\phi_{c p}$, which imply the following non-linear Phillips curve for price inflation ${ }^{10}$

$$
\phi_{c p} \pi_{t}\left(1+\pi_{t}\right) \bar{Y}+(\epsilon-1) Y_{t}=\epsilon m c_{t} Y_{t}+\beta E_{t} \phi_{c p} \pi_{t+1}\left(1+\pi_{t+1}\right) \bar{Y}
$$

The parameter $\phi_{c p}$ is a function of parameter of a traditional New-Keynesian Phillips curve, $\kappa_{p}$, such that in a first order approximation adjustment costs a la Rotemberg and Calvo would give

\footnotetext{
${ }^{10}$ We assume firms are risk neutral when it comes to the price-setting decision, instead of discounting the future using the intermediary discount factor. This assumption has no implication since we introduce both wages and prices Phillips curve in a first order approximation to reduce the potential instability of the system.
} 
the same dynamics (see Lombardo and Vestin [32]). The marginal cost $m c$ is function of the factor prices (wage and rental rate of capital) and TFP:

$$
m c_{t}=\frac{w_{t}^{\alpha} r_{k, t}^{1-\alpha}}{A_{t} \alpha^{\alpha}(1-\alpha)^{1-\alpha}}
$$

Total factor productivity is a stationary exogenous process governed by a temporary and persistent shock $\varepsilon_{t}^{A}$ and $\varepsilon_{t}^{g}$,respectively

$$
\begin{aligned}
A_{t} & =g_{t}+\rho_{A} A+\left(1-\rho_{A}\right) A_{t-1}+\sigma_{A} \varepsilon_{t}^{A} \\
g_{t} & =\rho_{g} g_{t-1}+\sigma_{g} \varepsilon_{t}^{g}
\end{aligned}
$$

Capital goods producers Capital goods producers, owned by households, buy output $I_{t}$ to produce investment goods (new capital) which are sold to the intermediary sector at a price $Q_{t} \cdot{ }^{11}$ Since there is no difference between new and old capital, the real value of the capital stock is simply $q_{t} K_{t}$, where $q_{t}=Q_{t} / P_{t}$. Hence, the intermediary sector's valuation of capital, $q_{t}$, also drives investment. Given $q_{t}$, investment is chosen to solve

$$
\max _{I_{t}} \widetilde{I}_{t} \widetilde{I}_{t}-I_{t}-\Phi\left(I_{t} / K_{t}, K_{t}\right)
$$

where $\Phi\left(I_{t} / K_{t}, K_{t}\right)=0.5 \kappa\left(I_{t} / K_{t}-\delta\right)^{2} K_{t}$ is the second term in cost function which depends on aggregate capital while technology is such that new units of physical capital are equal to output used as inputs $\widetilde{I}_{t}=I_{t}$. Optimality implies ${ }^{12}$

$$
I_{t} / K_{t}=\delta+\frac{\left(q_{t}-1\right)}{\kappa}
$$

Capital producers rebate their profits to households which are zero only in the deterministic steady state: $D_{t}^{k}=q_{t} I_{t}-I_{t}-\Phi\left(I_{t} / K_{t}, K_{t}\right)=\left(q_{t}-1\right)\left(\delta+\frac{q_{t}-1}{2 \kappa}\right) K_{t} \cdot{ }^{13}$

\subsection{Financial Sector}

There is a separation between the ownership and control of an intermediary, and a manager makes all investment decisions of the intermediary. The manager raises funds from households in two

\footnotetext{
${ }^{11}$ In the deterministic steady state capital producers make zero profits. A $q_{t}>1\left(q_{t}<1\right)$ implies positive (negative) profits: $\operatorname{div}_{t}=\left(q_{t}-1\right)\left(\delta+\frac{q_{t}-1}{2 \kappa}\right) K_{t}$

${ }^{12}$ Notice that the relation between investment and $\mathrm{q}$ is the same as the one prevailing in presence of capital adjustment costs in a traditional real business cycle model (Hayashi 1982).

${ }^{13}$ It is straightforward to see that profits are positive if and only if $q_{t}>1$.
} 
forms, equity and debt $W_{t}=V_{t}+B_{t}$ which are used to purchase capital. The goal of the manager is to maximize his reputation which is determined by the history of realized returns on intermediary equity

$$
e_{t}=e_{t-1} m \tilde{R}_{t}
$$

where $m>0$ is a constant describing the risk aversion of the manager and $\tilde{R}$ is the intermediary's real return on equity which is a combination of the return on investment and the cost of funds

$$
\tilde{R}_{t}=\theta_{t-1} R_{t}-\left(\theta_{t-1}-1\right)\left(1+\tau_{t}\right) R_{t-1}^{f}=R_{t}+\left(\theta_{t-1}-1\right)\left(R_{t}-\left(1+\tau_{t}\right) R_{t-1}^{f}\right),
$$

where $\theta_{t}>1$ is the financial intermediaries leverage which amplifies the return on investment $R_{t}$. In other words, $\theta_{t}$ is the ratio of assets and the equity raised by an intermediary while $\theta_{t}-1$ is the debt-to-equity ratio. In equilibrium, we have that $\theta_{t}=W_{t} / V_{t}$ and $\theta_{t}-1=B_{t} / V_{t}$. As far as the equity premium is positive $E_{t} R_{t+1}-R_{t}^{f}>0$ higher leverage is expected to increase the financial intermediary's return on equity. A macroprudential tool, $\tau_{t}$, is available to the government and will be described below.

Optimal leverage is determined by maximizing the manager's expected life-time (log) reputation which is consistent with the traditional mean-variance portfolio strategy ${ }^{14}$

$$
\theta_{t}=\frac{\widetilde{E}_{t} R_{t+1}-R_{t}^{f}}{m \operatorname{var}_{t}\left(R_{t+1}\right)}
$$

where $\widetilde{E}_{t} R_{t+1}=E_{t} R_{t+1}+v_{t}$ and $v_{t}$ can be interpreted as a demand shock which follows a first order autoregressive process. The realized return on investment is given by

$$
R_{t}=\frac{q_{t} K_{t}+D_{t}}{q_{t-1} K_{t-1}}
$$

Where $D_{t}$ are dividends from firms $D_{t}=Y_{t}-\delta K_{t}-w_{t} L_{t}$. The Sharpe ratio is defined as the risk premium on an investment divided by its risk:

$$
S_{t}^{a}=m \theta_{t} \sigma_{t+1}^{R}
$$

where $\sigma_{t+1}^{R}=\sqrt{\operatorname{var}_{t}\left(R_{t+1}\right)}$. The Sharpe ratio is equal to the riskiness of the intermediary portfolio, $\theta_{t} \sigma_{t+1}^{R}$, times the risk aversion of the financial intermediary $m$. If the intermediary sector bears more risk in its portfolio the Sharpe ratio will rise.

It is instructive to consider the amplifying effects of a binding capital constraint. If $e_{t}<$ $(1-\lambda) \bar{W}^{\gamma} W_{t}^{1-\gamma}$, then the intermediary sector only raises $V_{t}=e_{t}$ of equity. The effect of negative

\footnotetext{
${ }^{14}$ See He and Krishnamurty [28] on how to derive the optimality condition of the financial intermediary.
} 
shock in this state reduces $W_{t}=q_{t} K_{t}$, but reduces $e_{t}=V_{t}$ more through two channels. First, since the intermediary sector is levered the return on equity is a multiple of the underlying return on the intermediary sector's assets. Second, reputation, $e_{t}$, moves more than one-for-one with the return on equity since the risk aversion of the financial intermediary, $m$, is larger than one $\left(e_{t}=e_{t-1} m \tilde{R}_{t}\right)$. Hence, negative shocks are amplified and cause leverage to actually rise when the capital constraint binds. Higher leverage implies a higher Sharpe ratio on capital investment, $S_{t}^{a}$, which in turn implies that the price of capital, $q_{t}$, must be lower in order to deliver the higher expected returns (from 2.5). A lower price of capital will in turn further depress investment which depends on $q_{t}$.

We can define the mis-pricing of risk as

$$
\omega_{t}=\beta E_{t} \frac{u_{c, t+1}}{u_{c, t}}\left(\widetilde{R}_{t+1}-R_{t}^{f}\right) .
$$

Notice that in the absence of financial frictions $\omega_{t}=0$ at all times (see Appendix). The mispricing of risk is counter-cyclical in that there is underpricing of risk during good times and vice versa. This distortion is also a key feature of the model that helps understand why risks can buildup during good times.

\subsection{Monetary Policy}

We assume that the monetary authority sets the short-term nominal interest rate according to a simple Taylor-type rule (Taylor [41]) where the risk-free nominal rate responds to its lagged value, price and wage inflation, a measure of economic activity $x$, and a zero-mean measure of financial vulnerability (leverage or mispricing of risk) $\vartheta_{t}$,

$$
\begin{aligned}
i_{t} & =\phi_{i} i_{t-1}+\left(1-\phi_{i}\right)\left(\phi_{\pi} \pi_{t}^{c}+\phi_{x} x_{t}+\phi_{\theta} \vartheta_{t}\right)+\epsilon_{t}^{m} \\
\pi_{t}^{c} & =\left(1-\phi_{w}\right) \pi_{t}+\phi_{w} \pi_{t}^{w}
\end{aligned}
$$

where $\pi_{t}^{c}$ is a composite wage and price inflation index. ${ }^{15}$ We also append a monetary policy shock $\epsilon_{t}^{m}$, which is possibly autocorrelated, when we study the transmission mechanism of monetary policy.

\subsection{Macroprudential Policy}

Within our framework there are two related motives for a macro-prudential policy that encourages banks to use outside equity and discourages the use of short term debt. First, households do

\footnotetext{
${ }^{15}$ In models with both sticky prices and wages it can be proved that under some conditions it is optimal to respond to the composite inflation index. In our baseline setup, a parameter $\phi_{w} \simeq 0.5$ gives a good welfare performance.
} 
not fully internalize the systemic effect of their portfolio allocation choices and their investment in equity is price insensitive. Second, investment decision by financial intermediaries are driven by the objective of maximizing total returns in a way that does not fully capture the household preference for risk and their externality on asset prices. The two distortions imply that risk is mispriced and, thus, asset prices are distorted.

A macroprudential policy

$$
\tau_{t}=\bar{\tau}+\varphi\left(\theta_{t}-E \theta_{t}\right)
$$

reacts to deviations of leverage from its unconditional mean, increasing the cost of issuing debt during periods of high leverage. The rule reduces the sensitivity of the financial sector to shocks hitting the real economy. In the stationary equilibrium the tax is set to make the macroprudential policy neutral (we set $\bar{\tau}=0$ while $E\left(\theta_{t}-E \theta_{t}\right)=0$ ), so that the net impact on intermediary's revenues is zero. However, the policy raises the relative attractiveness to intermediaries of issuing outside equity. ${ }^{16}$

\subsection{Equilibrium conditions and Aggregation}

Goods market clearing implies that output is either consumed or invested

$$
Y_{t}=C_{t}+I_{t}+\frac{1}{2} \kappa\left(i_{t}-\delta\right)^{2} K_{t}+0.5\left(\phi_{c p} \pi_{t}^{2}+\phi_{c w} \pi_{w, t}^{2}\right) \bar{Y}
$$

The value of the financial sector portfolio has to be equal to the overall households' financial investment in the financial intermediaries: $Q_{t} K_{t}=W_{t}=V_{t}+B_{t}$.

Finally, aggregating reputation $e_{t}$ across financial intermediaries, $\mathbf{S}_{t}$, since a given manager may die at any date at a constant Poisson intensity of $\eta>0$, the law of motion of the aggregate health (reputation) of the financial sector $\mathbf{S}_{t}$ is

$$
\mathbf{S}_{t}=\mathbf{S}_{t-1}\left(m \tilde{R}_{t}-\eta\right)
$$

hence, in equilibrium, the overall financial sector equity is given by

$$
V_{t}=\min \left(\mathbf{S}_{t},(1-\lambda) \bar{W}^{1-\gamma} W_{t}^{\gamma}\right) .
$$

\footnotetext{
${ }^{16}$ The macroprudential policy rule applies to all financial intermediaries. There are several practical issues related to using macroprudential policy that go beyond the scope of this paper. See e.g. Gelati and Moessner [20] for a discussion of issues such as risks shifting from one part of the financial system to another, which could potentially undermine the objectives of the policy measure.
} 


\section{Quantitative analysis}

In this section we show that the model has reasonable quantitative properties. We then use the model to evaluate the performance of alternative monetary policy rules. ${ }^{17}$ Non-linear models should preferably be solved with global methods. Due to the curse of dimensionality, however, these can be applied only to relatively small models with a limited number of state variables. Following Dewatcher and Wouters [17] we replace the occasionally binding constraint (2.6) with a differentiable function

$$
V_{t}=\frac{(1-\lambda) \bar{W}^{\gamma} W_{t}^{1-\gamma}}{1+\gamma_{1}\left(\frac{\bar{W}}{\mathbf{S}_{t-1}-\mathbf{S}}\right)^{3}} .
$$

which captures the essential features of the equity constraint, which is higher cost of raising equity during bad times. ${ }^{18}$

\subsection{Calibration}

The two Tables below list the choice of parameter values for our model. There are [20] main parameters. Seventeen are conventional. Three $\lambda, \gamma, m$ are specific to our model. We follow the literature as closely as possible to choose our parameters (see He and Krishnamurthy [28] and Dewachter and Wouters [17]) with the exception of $\gamma$ which governs the procyclicality of leverage. The annual discount rate, $\beta$, is set at 0.96 and the steady-state returns are defined consistently with this parameter. The depreciation rate, $\delta$, is assumed to be $10 \%$. The elasticity of intertemporal substitution for the households, $\sigma$, and the inverse of the Frisch labor elasticity, $\phi_{L}$, are both set equal to one. The habit parameter is equal to 0.3. The CD-labor share, $\alpha$, is set at 0.6. The capital adjustment cost is set at a value of 25 which produces a realistic relative volatility of consumption and investment in our model. The price and the wage inflation have a moderate sensitivity to their respective markups with wages behaving more sticky $\left(\kappa_{W}=0.02\right)$ than prices $\left(\kappa_{\pi}=0.10\right)$. Wages are partially indexed to price inflation $\gamma_{w}=0.5$. The fixed cost in production is equal to $20 \%$ of output and this choice also determines the average markup in price setting and the corresponding elasticity of substitution between individual goods. Fixed costs and nominal stickiness are important in the model as determinants of the amount of operational risk, that is the risk directly related to the volatility of the dividend flow paid out by the firms. Finally, in the

\footnotetext{
${ }^{17}$ The simulation outcomes are generated with the third-order perturbation procedures available in Dynare 4.1.1.

${ }^{18}$ An alternative interpretation of equation 2.6 would be as a penalty function approach used to capture the inequality constraint on equity (Rotemberg and Woodford [35] and Kim et al [30]).
} 
baseline case monetary policy is responding to the inflation composite deviations from target with an elasticity of 1.5 .

\begin{tabular}{lll} 
Parameter & Value & Description \\
\hline$\beta$ & 0.6 & Discount factor \\
$h$ & 0.3 & Habit \\
$\psi$ & 1 & Steady state labor \\
$\phi_{L}$ & 1 & Inverse Frisch labor elasticity \\
$\sigma$ & 1 & Intertemporal. elasticity of substitution \\
$\gamma_{w}$ & 0.5 & Wage indexation \\
$\delta$ & 0.10 & Depreciation of capital a.r. \\
$\alpha$ & 0.6 & Output elasticity of labor \\
$\Phi$ & 0.2 & Fixed cost in production \\
$\eta$ & 0.10 & Financial interm. exit rate \\
$\lambda$ & 0.5 & Liquidity service share \\
$m$ & 3.75 & Manager risk aversion \\
$\gamma$ & 1 & Leverage cyclicality \\
$\kappa_{p}$ & 0.10 & Price stickiness \\
$\kappa_{w}$ & 0.02 & Wage stickiness \\
\hline \hline
\end{tabular}

We calibrate the demand and supply processes to match data moments of macroeconomic variables. We use postwar US data from $1960 Q 1$ to 2014Q2, for PCE inflation, real GDP, private consumption, and private business fixed investment to match growth rate volatilities with the ones implied by the model. ${ }^{19}$ The model is able to replicate the standard deviations of key macro variables during normal times and during recessions (defined using the NBER recession dating) and the fall in average growth between normal times and recessions (see Table 1). ${ }^{20}$

\begin{tabular}{lll} 
Parameter & Value & Description \\
\hline$\rho_{A}$ & 0.92 & Supply process persistence \\
$\rho_{g}$ & 0.65 & Demand process persistence \\
$\sigma_{A}$ & 0.005 & Supply shock standard dev. \\
$\sigma_{g}$ & 0.003 & Demand shock standard dev. \\
\hline \hline
\end{tabular}

[Table 1. Summary Statistics]

We also choose our parameter $\gamma$ such that the correlation between leverage and the value of financial intermediaries' portfolio $W_{t}$ is as in the data during normal times and during crisis periods.

\footnotetext{
${ }^{19}$ We simulate the model, starting from the deterministic steady state, for 3,000 periods. We discard the first 500 periods as a burn-in to eliminate the transition from the deterministic steady state of the model to the ergodic distribution of the state variables.

${ }^{20}$ Bad times are defined using the NBER recession dating. Standard deviations for both normal and bad times are centered around the unconditional sample mean.
} 
As documented by Adrian and Shin [1] changes in debt are correlated with changes in the value of total assets while changes in equity are mostly uncorrelated to total assets. The interpretation is that financial intermediaries expand their balance sheet by issuing debt rather than raising equity. The exception is severe financial crisis periods when fire sales reduce the value of assets while the value of liabilities is mostly unchanged. If equity is marked to market then the value of equity follows the reduction in total assets. Figure 1 shows that the model is able to replicate these salient features of the data for broker dealers. As pointed out in the literature, however, the procyclicality of commercial bank leverage (and the change in the size of their balance sheet) is substantially lower. Hence, to the extent that overall financial sector leverage is less pro-cyclical than brokerdealer leverage, our calibration is biased in favor of monetary policy leaning against leverage.

[Figure 1. Cyclical Properties of Debt and Equity].

Following He and Krishnamurthy [28] we define systemic crisis as periods where the equity constraint binds. In this situation the elasticity of equity to reputation is equal to $1\left(V_{t}=\mathbf{S}_{t}\right)$. Our use of a differentiable function makes makes the definition of a systemic crisis slightly more arbitrary since the constraint is affecting the economy also for situations when the elasticity of equity to reputation is less than 1 . Hence, we define recessions as periods of moderate to strong financial stress when the elasticity is greater than 0.5 which implies a threshold for reputation of $\mathbf{S}_{t}<0.95$. We define a systemic crisis when reputation is below 0.83 which implies an elasticity of equity to reputation greater than or equal to one. Under the baseline calibration the probability of a systemic crisis is about 3 percent, i.e. systemic crisis occur approximately every thirty years on average. This probability is chosen to reflect the observation that there have been three major financial crises in the US over the last 100 years. Finally, a severe systemic crisis is defined, on technical grounds, as a situation when reputation falls below a certain threshold which, in our third order approximation, implies a negative value for equity. This is a point of no return after which the system becomes unstable. Under our chosen approximation of the equity investment constraint, we pass the point of no return when $\mathbf{S}_{t}<0.66$.

\section{Model Analysis}

In this section we will explore how the model behaves under the baseline calibration. Since we use a third-order approximation, we also consider how impulse response functions change with the 
state of the economy: between a state with average reputation and a state with low reputation (a "bad" state).

\subsection{Financial cycle vs. business cycle}

Empirical literature has documented that the business cycle and the financial cycle (defined according to the choice of some financial variables) are not perfectly aligned (see Borio [9]). This observation has often been brought forward as evidence of a trade-off between systemic risk and output and inflation stabilization goals. Figure 2 shows the cross-correlation function between detrended output and leverage in the model and in the data (both in percent). Under the baseline calibration we find that leverage is more persistent than de-trended output (top left and bottom right hand side subplots in each panel show autocorrelations) and lags the business cycle. In the data, broker-dealer leverage is also positively and significantly correlated with the output gap, with the highest correlation at a few quarters lag.

[Figure 2. Correlation between Output and Leverage]

\subsection{Impact of a real shock to the financial sector and the amplification mechanism}

Figure 3 shows how supply shocks affect macroeconomic and financial variables. A negative productivity shock in the real sector reduces realized returns in the financial sector and its perception of health which, in turn, reduces risk appetite leading to excess pricing of risk. The corresponding lower asset price valuations, in a vicious feedback loop, imply lower investment and output. The same mechanism is amplified by the equity constraint in a bad state when financial sector reputation is already low. In this case we observe a sudden drop in the capacity of the financial sector to bear risk that exacerbates the initial reduction in investment and output. The equity premium (asset prices) increases (decrease) more substantially while leverage increases rather than decreasing in the baseline state.

[Figure 3. Negative Total Factor Productivity Shock]

\subsection{Impact of a monetary policy shock on the financial sector}

A surprise monetary policy tightening has a negative impact on output, inflation, and asset prices. Coupled with an increase in funding costs and the equity premium, this implies a reduction in 
the financial sector return on investment which reduces its reputation at impact. In general, the monetary policy shock leads to a reduction in leverage, however, if the surprise happens during a bad state the more persistent fall in asset prices - coupled with a deeper fall in output and inflation - triggers a sharper reduction in financial equity which can actually lead to a subsequent increase in leverage. The monetary policy surprise leads to losses without persistently altering risk taking behavior in the financial sector, which are more affected by the systematic monetary policy behavior (see below). The impact on systemic risk is, thus, mixed and is state dependent. In the bad state, after 4 quarters the probability of a more fragile financial sector (with negative reputation) after a surprise monetary policy tightening is actually higher than in absence of the shock.

[Figure 4a. and 4b. Monetary Policy Tightening Shock]

\section{Welfare Analysis}

Following Faia and Monacelli [19] and Gertler and Karadi [21], among others, we express the household utility function recursively ${ }^{21}$ :

$$
U_{t}=u\left(C_{t}, L_{t}\right)+\beta E_{t} U_{t+1}
$$

where $U_{t}=E_{t} \sum_{j=0}^{\infty} \beta^{j} u\left(C_{t+j}, L_{t+j}\right)$ denotes the utility function. We take a third-order approximation of $U_{t}$ around the deterministic steady state. Using the third-order solution of the model, we then calculate the unconditional expectation of the utility $U=E\left[U_{t}\right]$ (i.e., welfare, where $E$ denotes the unconditional expectations operator) in each of the separate cases of monetary and macroprudential policies. We rank alternative policies in terms of a steady state consumption equivalent, $\Delta$, given by the fraction of consumption loss required to equate welfare in the deterministic steady state, $U^{s s}(\Delta)$, to one resulting from using monetary and macroprudential policies, $U^{*}$. Hence the measure of welfare we use is the consumption equivalent value required for the household to be indifferent between $U^{s s}(\Delta)$ and $U^{*}$. A higher (less negative) $\Delta$ implies a lower consumption equivalent value is required for the household to be indifferent between the alternatives and hence indicates that the policy is more desirable from a welfare point of view. By imposing

\footnotetext{
${ }^{21}$ Given that it is a representative household model, the welfare function coincides with the household overall utility function.
} 
$U^{s s}=u(\Delta \bar{C}, \bar{L}) /(1-\beta)=U^{*}$ we have ${ }^{22}$

$$
\Delta=\frac{1}{(1-h) \bar{C}}\left\{\left[1+(1-\sigma)(1-\beta) U^{*}\right]^{\frac{1}{1-\sigma}}+\frac{\psi \bar{L}^{1+\phi_{L}}}{\left(1+\phi_{L}\right)}\right\}
$$

To find the optimal simple monetary and macroprudential policy rules, we then search numerically in the grid of parameters $\left\{\phi_{i}, \phi_{p}, \phi_{x}, \phi_{\theta}\right\}$ where we use the following grid $\phi_{i}=0, \phi_{p}=[1,3]$, $\phi_{x}=[0,2], \phi_{\theta}=[0,0.5]$, that optimizes $U$ in response to the shocks.

To compute welfare, we simulate the model for 100 years (400 quarters) after dropping the first 500 observations and compute the average value of $U_{t}$. If during the simulation reputation drops below a point of no return (about $\mathbf{S}_{t}<0.66$ ) we record the outturn as unstable (severe crisis) and move on to draw another seed. We repeat it until we have $N$ stable simulations. Finally, since some policy rules dramatically change the stability properties of the model we penalize instability by adjusting welfare and define adjusted (weighted) welfare as the average computable welfare times the frequency of stable simulations.

\subsection{Results in absence of systemic risk}

The standard New Keynesian results prevail in the absence of financial frictions. In particular, since the model includes nominal wage rigidities, it is optimal for the central bank to target a composite index which takes into account also wage inflation (see e.g. Erceg et al [18]). ${ }^{23}$ Also, once the composite inflation index is sufficiently stabilized, reacting to the level of output is not welfare improving (see Figure 5). ${ }^{24}$ Hence, we confirm the results in Schmitt-Grohé and Uribe [36] who also find that it is welfare reducing to respond to output. Since traditional results were derived in a linear-quadratic approach, our findings suggest that, in the absence of financial frictions, timevarying risk premia and higher order non-linearities do not alter the traditional policy prescription.

\footnotetext{
${ }^{22}$ We will present the results in terms of $100 \times(\Delta-1)$. Notice also that since the steady state is distorted it is possible, in principle, to obtain a $\Delta>0$.

${ }^{23}$ The reason is that fluctuations in both wage and price inflation and the output gap, generate a resource misallocation and a welfare loss. Hence, optimal policy should strike the right balance between stabilization of those three variables. The optimal policy can be approximated by a policy that stabilizes a weighted average of price and wage inflation, where the appropriate weights are function of the relative stickiness of prices and wages.

${ }^{24} \mathrm{An}$ intuition for why a policy of responding to output is not appropriate in response to supply shocks such as a technology shock, is that under such policy the nominal interest rate rises whenever output rises. This increase in the nominal interest rate in turn hinders prices falling by as much as marginal costs causing markups to increase. With an increase in markups, output does not increase as much as it would have otherwise, preventing the efficient rise in output.
} 
We will take these results as our benchmark against which we evaluate how the optimal simple rule can be augmented with financial variables once the financial sector is introduced.

[Figure 5. Welfare: Baseline without Systemic Risk ]

\subsection{Reacting to output: the volatility paradox}

Reacting to output (in addition to the usual prescription of the model without financial frictions) implies a reduction of macroeconomic volatilities, such as output volatility, during periods or relatively mild shocks - at the cost of higher inflation volatility. Compressing macroeconomic volatility, by reducing risk premia, also generates lower real rates which in turn increase asset prices and, thus, investment and capital stock above their efficient levels - average output is indeed higher. As a result, the financial sector has to finance, through borrowing and higher leverage, a larger investment portfolio. Even though apparently in better shape because of higher asset prices the financial sector is actually more vulnerable to boom-bust cycles when a series of benign shocks, which further increase leverage and compress risk premia, is followed by a series of negative shocks. Overall, depending on the severity of the crisis, welfare can be negatively affected by the intensification of tail events (Figure 7). Indeed, the number of simulations where reputation drops below its lower bound threshold increases. Hence, a reaction to output over and above the usual reaction is not warranted by financial stability issues.

[Figure 6. Welfare: Leverage vs. Output stabilization]

[Figure 7. Volatility Paradox: Distribution of Output, Inflation and Leverage]

\subsection{Reacting to leverage: risk of financial dominance and unintended consequences}

A systematic reaction to leverage improves welfare in normal times. However the improvement is small: a modest reaction to leverage, with $\phi_{\theta} \simeq 0.28$, which would typically induce a change in the policy rate that is 3 to 5 bps larger than otherwise, improves welfare by about 0.25 percent in terms of steady state consumption equivalent, under the baseline calibration (see Figure 6 and 8). Indeed, a modest systematic monetary policy of leaning against the wind implies a reduction in both inflation and output volatility. These results, however, are sensitive to the parametrization. First, the result depends on leverage being procyclical. Second, even when leverage is indeed procyclical, a higher weight on leverage in the monetary policy rule increases the frequency of 
severe crises (see Figure 8). As a result, even if the unadjusted welfare increases with a higher weight on leverage, the welfare measure adjusted for the probability of crisis eventually decreases as the weight on leverage increases. The reason is that crises are periods of sharp drops in asset prices, which lead to a reduction in equity greater than the reduction in debt-putting upward pressure on leverage. Hence, a policy rule that reacts to increases in leverage in these circumstances can exacerbate a crisis, penalizing our adjusted welfare metric. Indeed, even though the mass of leverage is more concentrated around a lower value, the tails of the distribution are actually larger (Figure 9 Panel B vs. Panel A). Finally, as the weight of leverage in the monetary policy rule results in higher volatility of inflation. Reacting to systemic risks therefore results in a trade-off between the traditional inflation mandate of monetary policy.

[Figure 8. Monetary Policy Trade-Offs: Leaning against Leverage]

[Figure 9. Distribution of leverage ]

\subsection{Reacting to mis-pricing of risk: a modest effect}

The reaction to the mis-pricing of risk, $\vartheta_{t}=\omega_{t}$, entails less destabilization. However, the overall welfare effects are smaller. The optimal coefficient found is 0.56 . Increasing the reaction does not lead to increased instability of the system but the benefits in terms of welfare vanish even in the presence of relatively mild shocks. Mis-pricing of risk is therefore not highly affected by monetary policy and as a result not a very appealing intermediate target (see Figure 10).

[Figure 10. Welfare: Risk Mis-pricing vs. Output stabilization]

\subsection{Macroprudential policy}

A macroprudential policy rule (similar to a countercyclical capital requirement) which imposes a countercyclical tax on financial intermediaries, thus increasing the cost of funding when it is low and leverage is high, delivers the largest welfare improvement across our rules. In particular, figure 11 shows that leaning-against-leverage performed through macroprudential policy relative to interest rate policy gives a relative welfare benefit up to $1.2 \%$ of steady state consumption equivalent. This difference is explained by the fact that the macroprudential policy is more targeted and aims at breaking the negative feedback loop which links equity availability to the financial sector and asset

prices (low returns-low equity-low asset prices-low returns). In comparison a policy rate that reacts

CInternational Monetary Fund. Not for Redistribution 
to leverage is a blunt tool which, in an effort to stabilize leverage, tends to destabilize inflation and reduce output. Indeed, the welfare increases from the macroprudential policy do not derive from stabilizing only in good times but also by mitigating the probability and severity of systemic events in the financial sector.

[Figure 11. Welfare: Macroprudential vs. Interest Rates]

\section{Conclusions}

To analyze the benefit of simple monetary policy rules in the presence of systemic risk, we have developed a model where systemic risk arises endogenously and the behavior of macroeconomic and financial variables approximates data. The findings of our analysis can be summarized as follows: A monetary policy tightening surprise does not necessarily reduce systemic risk, particularly when the state of the financial sector is fragile. The negative impact of the surprise tightening on output, inflation, asset prices, and the rise of funding costs for financial intermediaries implies a reduction in profitability of the financial sector without altering their risk taking behavior. Risk taking behavior is affected by systematic monetary policy reaction. The negative effects of a monetary policy surprise are mitigated when the financial sector is strong and the surprise is small.

Systematic policy based on a simple (Taylor type) policy rule that includes financial variables such as leverage, can improve welfare by striking a balance between inflation and output stabilization on the one hand and reducing the likelihood of financial stress on the other. A simple policy reaction to leverage, however, is not robust and is too simplistic. First, leaning against the wind requires that financial sector leverage is pro-cyclical. As discussed above, empirical evidence is mixed and suggests that pro-cyclicality varies across sectors and over time. Second, even if leverage is pro-cyclical, when leverage increases because of a sharp fall in asset prices, an increase in policy interest rates exacerbates the initial asset price correction. Leaning against leverage without clearly distinguishing why leverage is increasing could therefore lead to a policy mistake that exacerbates incipient financial stress, possibly inducing a full blown crisis. This result suggests that the monetary policy reaction should go beyond the simple rule described here. Alternative rules could incorporate a non-linear response that differentiates between leaning against the wind in normal times and crisis response one the economy is moving towards financial stress. Alternative financial variables such as measures of mis-pricing of risk have more appealing properties which make them preferable to react to in a simple rule. However, they are less affected by monetary policy, leading 
to only modest welfare improvements. Finally, a simple macroprudential rule which acts similarly to a counter-cyclical capital requirement (making it more costly to raise debt during good times and vice versa) is substantially better than the interest policy rule in limiting the buildup of leverage and preventing crisis. 


\section{References}

[1] Adrian, T., and Shin, H., (2013), "Procyclical Leverage and Value-at-Risk", National Bureau of Economic Research, Working Paper Series 18943.

[2] Adrian, T., D. Covitz, N. Liang, (2014), "Financial Stability Monitoring", Federal Reserve Bank of New York Staff Reports, N 601.

[3] Ajello, A., Laubach, T., Lopez-Salido, D., and Nakata., T., (2015), "Financial Stability and Optimal Interest-Rate Policy", working paper, Federal Reserve Board.

[4] Angeloni, I., and Faia, E., (2013), "Capital regulation and monetary policy with fragile banks," Journal of Monetary Economics, Elsevier, vol. 60(3), pages 311-324.

[5] Bagehot, W., (1873), "Lombard Street, a description of the money market", Scriber, Armstrong, and Co, New York.

[6] BIS 2011. "The Transmission Channels Between the Financial and Real Sectors: A Critical Survey of the Literature." BIS Working Paper 18.

[7] Bernanke, B., and Gertler, M., (2001), "Should Central Banks Respond to Movements in Asset Prices?" American Economic Review, 91(2): 253-257

[8] Bernanke, B.S.,Gertler,M.,Gilchrist,S., (1999)."The financial accelerator in a quantitative business cycle framework". In: Taylor, J.B., Woodford, M.(Eds.), Handbook of Macroeconomics, vol.1., Elsevier, Amsterdam, TheNetherlands, pp. 1341-1393. (Chapter21).

[9] Borio, C., (2014), "The financial cycle and macroeconomics: What have we learnt?", Journal of Banking \& Finance, Elsevier, vol. 45(C), pages 182-198.

[10] Brunnermeier, M., and Sannikov, Y., (2014), "A Macroeconomic Model With A Financial Sector". American Economic Review 104.2: 379-421.

[11] Carlstrom, C. T., and Fuerst, T. S. (1997), "Agency costs, net worth, and business fluctuations: A computable general equilibrium analysis", American Economic Review, 893-910. 
[12] Carlstrom, C., T., Fuerst, T., S., and Paustian, M., (2010), "Optimal Monetary Policy in a Model with Agency Costs", Journal of Money, Credit and Banking 42 (s1): 7-70.

[13] Clouse, J.,.(2013), "Monetary Policy and Financial Stability Risks," Finance and Economics Discussion Series 2013-41. Board of Governors of the Federal Reserve System (U.S.).

[14] Christiano, L., Eichenbaum, M., and Evans, C., (2005), "Nominal Rigidities and the Dynamics Effects of a Shock to Monetary Policy", Journal of Political Economy 113 (1), 1-45.

[15] Cociuba, S., Shukayev, M., and Ueberfeldt, A., (2012). "Collateralized Borrowing and Risk Taking at Low Interest Rates?," University of Western Ontario, Economic Policy Research Institute Working Papers 20121.

[16] De Groot, O., (2014). "The Risk Channel of Monetary Policy," Finance and Economics Discussion Series 2014-31. Board of Governors of the Federal Reserve System (U.S.).

[17] Dewachter,H., Wouters, R., (2014), "Endogenous risk in a DSGE model with capitalconstrained financial intermediaries", Journal of Economic Dynamics and Control, 43: 241268.

[18] Erceg, C., Henderson, D., and Levin, A., (2000), "Optimal monetary policy with staggered wage and price contracts", Journal of Monetary Economics, Elsevier, vol. 46(2), pages 281-313, October.

[19] Faia, E., and Monacelli, T., (2007), "Optimal Interest Rate Rules, Asset Prices and Credit Frictions", Journal of Economic Dynamics and Control, vol. 31(10), 3228-3254.

[20] Galati, G., and Moessner, R., (2013), "Macroprudential Policy - A Literature Review," Journal of Economic Surveys, Wiley Blackwell, vol. 27(5), pages 846-878, December.

[21] Gertler, M., and Karadi, P., (2011), "A model of unconventional monetary policy", Journal of Monetary Economics, Elsevier, vol. 58(1), pages 17-34, January.

[22] Gilchrist, S., and Leahy, J., (2002), "Monetary policy and asset prices," Journal of Monetary Economics, Elsevier, vol. 49(1), pages 75-97, January.

[23] Greenlaw, D., Hatzius, J., Kashyap, A., and Shin, H. (2008): "Leveraged Losses: lessons from the Mortgage market Meltdown", Proceedings of the U.S. Monetary Policy Forum 2008. 
[24] Greenspan, A., (2002). "Opening Remarks," Federal Reserve Bank of Kansas City Economic Symposium Rethinking Stabilization Policy: 1-10.

[25] Greenwood, J., Hercowitz, Z., and Huffman, G., (1988), "Investment, capacity utilization, and the real business cycle", American Economic Review 78 (3): 402-17.

[26] Guerrieri, L., and Iacoviello, M., (2015), "Occbin: A Toolkit to Solve Models with Occasionally Binding Constraints Easily", Journal of Monetary Economics, March, vol. 70, pages 22-38.

[27] Hayashi, F., (1982), "Tobin's marginal Q and average Q: A neoclassical interpretation", Econometrica, 50, 215-224.

[28] He, Z., and Krishnamurthy, A., (2014), "A Macroeconomic Framework for Quantifying Systemic Risk", NBER Working Papers 19885, National Bureau of Economic Research, Inc.

[29] Kalemli-Ozcan, S., Sorensen, B., and Yesiltas, S. (2012): "Leverage Across Firms, Banks and Countries", Journal of International Economics 88(2).

[30] Kim, S., Kollmann, R., and Kim, J., (2010) "Solving the incomplete market model with aggregate uncertainty using a perturbation method", Journal of Economic Dynamics and Control 34(1), 50-58.

[31] Kiyotaki, N., and Moore, J., (1997) "Credit cycles" Journal of Political Economy 105(2), $211-48$

[32] Lombardo, G., \& Vestin, D., (2008). "Welfare implications of Calvo vs. Rotemberg-pricing assumptions",. Economics Letters, 100(2), 275-279.

[33] Nuno, G., and Thomas, D. (2013): "Bank Leverage Cycles", ECB working paper 1524.

[34] Quint, D., and Rabanal, P., (2014), "Monetary and Macroprudential Policy in an Estimated DSGE Model of the Euro Area", International Journal of Central Banking, Vol. 10, No. 2, pp. 169-236.

[35] Rotemberg, J., and Woodford, M., (1999), "Interest rate rules in an estimated sticky price model" In 'Monetary Policy Rules' NBER Chapters (National Bureau of Economic Research) pp. $57-126$. 
[36] Schmitt-Grohe, S., and Uribe, M., (2007), "Optimal, Simple, and Implementable Monetary and Fiscal Rules", Journal of Monetary Economics 54, September, 1702-1725.

[37] Smets, F., and Wouters, R., (2007), "Shocks and Frictions in US Business Cycles: A Bayesian DGSE Approach"," American Economic Review 97(3), 586-606.

[38] Svensson, L., E., O., (2010), "Inflation Targeting", in Friedman, Benjamin M., and Michael Woodford, eds., Handbook of Monetary Economics, Volume 3B, chapter 22, Elsevier 2010.

[39] Svensson, L., E., O., (2014), Inflation Targeting and "Leaning against the Wind", International Journal of Central Banking, 10(2), 103-114.

[40] Taylor, J., B., (1979), "Estimation and Control of a Macroeconomic Model with Rational Expectations," Econometrica 47(5), 1267-1286.

[41] Taylor, J., B., (1993), "Discretion versus policy rules in practice", Carnegie-Rochester Conference Series on Public Policy 39, 195-214.

[42] Woodford, M., (2012), "Inflation Targeting and Financial Stability," Sveriges Riksbank Economic Review, 2012:1, p. 7-32. 


\section{Appendix}

\section{.1. The Efficient Allocation}

We will solve for the (constrained) efficient allocation when the financial sector is a veil and all nominal rigidities are eliminated.

Household Sector (no financial sector) A representative household maximizes the expected utility flow:

$$
U_{t}=E_{0} \sum_{t=0}^{\infty} \beta^{t} u\left(C_{t}, L_{t}\right),
$$

where $\beta$ is the discount factor and $C_{t}$ and $L_{t}$ denotes consumption and labor effort respectively. The instantaneous utility function is specified as in the text while the intertemporal budget constraint which is given by:

$$
C_{t}+q_{t} I_{t}=w_{t} L_{t}+r_{t}^{k} K_{t-1}+D i v_{t}^{c p}+D i v_{t}
$$

Capital producers rebate their profits Div $v_{t}^{c p}$ to households which are assumed to invest directly in

the capital stock, $I$, and rent it to firms for a return $r^{k}$. New capital is purchased at a price $q$ from capital producers. The law of motion of physical capital is

$$
K_{t}=(1-\delta) K_{t-1}+I_{t}
$$

The optimal intertemporal condition for capital accumulation provides the following intertemporal condition.

$$
q_{t}=\beta E_{t} \frac{u_{c, t+1}}{u_{c, t}}\left[(1-\delta) q_{t+1}+r_{t+1}^{k}\right]
$$

When the price of capital is expected to raise, capital gains adds to the rental rate of capital.

The labor supply is given by

$$
w_{t}=-u_{l, t} / u_{c, t}=\psi L_{t}^{\phi_{L}}
$$

Household (explicit financial sector) It is possible to split the household problem in introduce a financial sector. Assume household do not accumulate physical capital directly but own financial intermediaries which, in turn, invest in physical capital and own final goods firms. The household budget constraint is modified to include the possibility of buying banks' shares and in risk-free debt with banks:

$$
C_{t}+p_{t}^{s} x_{t}+B_{t}=w_{t} L_{t}+\left(p_{t}^{s}+d_{t}\right) x_{t-1}+\left(1+r_{t-1}\right) B_{t-1}+D i v_{t}^{c p}
$$


The household maximization problem gives two equations in addition to the consumption-leisure choice:

$$
\begin{gathered}
p_{t}^{s}=\beta E_{t} \frac{u_{c, t+1}}{u_{c, t}}\left[p_{t+1}^{s}+d_{t+1}\right] \\
1 /\left(1+r_{t}\right)=\beta E_{t} \frac{u_{c, t+1}}{u_{c, t}}
\end{gathered}
$$

It is also possible to define $V_{t}=p_{t}^{s} x_{t}, \widetilde{R}_{t+1}=\left(p_{t+1}^{s}+d_{t+1}\right) / p_{t}^{s}$ and $W_{t}=V_{t}+B_{t}$ such that we have

$$
\begin{gathered}
C_{t}+W_{t}=w_{t} L_{t}+\widetilde{R}_{t} V_{t-1}+\left(1+r_{t-1}\right) B_{t-1}+D i v_{t}^{c p}, \\
1=\beta E_{t} \frac{u_{c, t+1}}{u_{c, t}}\left[\widetilde{R}_{t+1}\right]
\end{gathered}
$$

Accumulation of physical capital is done by banks. Since $q_{t}$ is the price of (new and old ) installed capital, the value of total capital is $q_{t} K_{t}$. The bank can issue shares and one-period debt. The bank maximizes current and future dividends per share using the discount factor $m_{t, t+j}:{ }^{25}$

$$
E_{0} \sum_{t=0}^{\infty} m_{0, t} d_{t}
$$

subject to

$$
\begin{aligned}
D_{t} & =d_{t} x_{t-1}=r_{t}^{k} K_{t-1}+\operatorname{Div}_{t}+B_{t}+p_{t}^{s} \Delta x_{t}-q_{t} I_{t}-\left(1+r_{t-1}\right) B_{t-1} \\
K_{t} & =(1-\delta) K_{t-1}+I_{t}
\end{aligned}
$$

The consolidated budget constraint is also identical to the previous one. We define the adjusted discount factor as $\tilde{m}_{t, t+1}=m_{t, t+1} x_{t-1} / x_{t}$. The first order conditions, after some algebra, are analog

\footnotetext{
${ }^{25}$ The timing is as follows: banks can use debt and cash flow from physical capital to pay dividends to the current shareholders $d_{t} x_{t-1}+N d_{t}=r_{t}^{k} K_{t-1}+\operatorname{Div}_{t}+B_{t}-\left(1+r_{t-1}\right) B$, where $N d_{t} \geq 0$ are non distributed dividends (retained earnings). After that, new shares are potentially issued to investment together with retained earnings $q_{t} I_{t}=p_{t}^{s} \Delta x_{t}+N d_{t}$. Hence, new shares will receive tomorrow's dividends consistently with the convention used in the household problem to determined demand for shares. Only when the constraint is binding $N d_{t}=0$ the two problems differ. We assume it does not bind.
} 
to .2

$$
\begin{aligned}
p_{t}^{s} & =E_{t} \tilde{m}_{t, t+1}\left[p_{t+1}^{s}+d_{t+1}\right] \\
q_{t} & =E_{t} \tilde{m}_{t, t+1}\left[(1-\delta) q_{t+1}+r_{t+1}^{k}\right] \\
1 & =E_{t} \tilde{m}_{t, t+1}\left[1+r_{t}\right]
\end{aligned}
$$

If the bank is rasing capital to finance investment then it discounts more future returns. If $m_{t, t+1}=\beta \frac{u_{c, t+1}}{u_{c, t}}$, equilibrium in the bond market implies that $E_{t} \tilde{m}_{t, t+1}=E_{t} m_{t, t+1} x_{t-1} / x_{t}=$ $E_{t} m_{t, t+1}$, which implies $x_{t}=x_{t-1}$. Hence, allocation is the same as above and the banking sector is a veil.

\section{.2. Real Sector (Production)}

Following the New Keynesian framework, there is a continuum of monopolist firms that produce differentiated goods according to the technology

$$
Y_{t}=F\left(L_{t}, K_{t}^{d}\right)-\Phi_{Y}=A_{t} L_{t}^{\alpha} K_{t-1}^{1-\alpha}-\Phi_{Y}
$$

where the demand for individual firm's output is given by $y_{t}^{*}=\left(p_{t}^{*} / P_{t}\right)^{-\epsilon} Y_{t}$, while they pay wages $w$ and rental rates $r^{k}$ for labor and capital. We already impose the equilibrium condition that demand for capital is equal to the supply $K_{t}^{d}=K_{t}$. The marginal cost $m c_{t}$ is function of the factor prices (wage and rental rate of capital) and TFP. In equilibrium, since prices are flexible, is equal to the inverse of the markup $\mu_{p}=\epsilon /(\epsilon-1)$.

$$
m c_{t}=\frac{w_{t}^{\alpha} r_{k, t}^{1-\alpha}}{A_{t} \alpha^{\alpha}(1-\alpha)^{1-\alpha}}=1 / \mu_{p}
$$

The labor demand is given by

$$
\begin{aligned}
w_{t} & =\alpha A_{t}\left(K_{t-1} / L_{t}\right)^{1-\alpha} / \mu_{p} \\
r_{t}^{k} & =(1-\alpha) A_{t}\left(L_{t} / K_{t-1}\right)^{\alpha} / \mu_{p} \\
\operatorname{Div}_{t} & =\left(Y_{t}-\bar{Y}\right) / \epsilon
\end{aligned}
$$

We choose $\Phi=\bar{Y} /(\epsilon-1)$ to guarantee zero profits in the non-stochastic steady state. ${ }^{26}$

\footnotetext{
${ }^{26}$ Notice that total costs are equal to marginal costs times output gross of the fix cost: $T C=m c(Y+\Phi)$.
} 
Capital goods producers Capital goods producers, owned by households, produce investment goods (new capital) which are sold to the intermediary sector at a price $q_{t}{ }^{27}$ Hence, the intermediary sector's valuation of capital, $q_{t}$, also drives investment. Given $q_{t}$, investment is chosen to solve,

$$
\max _{i_{t}} q_{t} I_{t}-I_{t}-\Phi\left(I_{t} / K_{t-1}, K_{t-1}\right) .
$$

where $\Phi\left(I_{t} / K_{t-1}, K_{t}\right)=0.5 \kappa\left(i_{t}-\delta\right)^{2} K_{t}$ is a cost function which depends on aggregate capital and include capital adjustment costs. Optimality implies ${ }^{28}$

$$
I_{t} / K_{t}=\delta+\frac{\left(q_{t}-1\right)}{\kappa}
$$

In the deterministic steady state capital producers earn zero profit, however, when $q_{t}>1\left(q_{t}<1\right)$ we they earn positive (negative) profits: $\operatorname{Div}_{t}^{c p}=\left(q_{t}-1\right)\left(\delta+\frac{q_{t}-1}{2 \kappa}\right) K_{t}$.

Resource Constraint (Equilibrium) The equilibrium in the capital market implies that $K_{t}^{d}=$ $K_{t-1}$. The equilibrium in the good market implies that output is ${ }^{29}$

$$
Y_{t}=C_{t}+I_{t}+\Phi\left(I_{t} / K_{t-1}, K_{t-1}\right)
$$

\footnotetext{
${ }^{27}$ In the deterministic steady state capital producers make zero profits. A $q>1(q<1)$ implies positive (negative) profits: $\operatorname{div}_{t}=\left(q_{t}-1\right)\left(\delta+\frac{q_{t}-1}{2 \kappa}\right) K_{t}$

${ }^{28}$ Notice that the relation between investment and $q_{t}$ is the same as the one prevailing in presence of capital adjustment costs in a traditional real business cycle model (Hayashi [27]).

${ }^{29}$ It is straightforward to derive the resource constraint from budget constraint of the household.
} 


\section{Tables and Figures}

Table 1. Summary Statistics (in percent)

Data

\begin{tabular}{|r|ccc|}
\hline \multicolumn{4}{|c|}{$\begin{array}{c}\text { Moments based on NBER Recessions } \\
\text { (1960Q1 - 2014Q2) }\end{array}$} \\
\hline Real GDP Growth Rate & Std Dev Recession & Std Dev Non-Recession & Mean Resession - Mean Non-Recession \\
Private Consumption & 5.58 & 2.94 & -5.39 \\
Private Business Fixed investment & 4.57 & 2.34 & -3.67 \\
Hours worked & 14.98 & 7.12 & -14.91 \\
\hline
\end{tabular}

\section{Baseline Simulation.}

\begin{tabular}{|r|ccc|}
\hline \multicolumn{4}{|c|}{ Model based moments } \\
\hline Real GDP Growth Rate & Std Dev Recession & Std Dev Non-Recession & Mean Resession - Mean Non-Recession \\
\hline Private Consumption & 6.00 & 4.07 & -4.06 \\
Private Business Fixed investment & 2.87 & 2.38 & -1.62 \\
Hours worked & 17.50 & 10.48 & -12.68 \\
\hline
\end{tabular}

Note: Standard deviations are centered on the sample mean. The third column represents the difference in average growth rates between crisis and non-crisis periods. 
Figure 1. Cyclical Properties of Debt and Equity
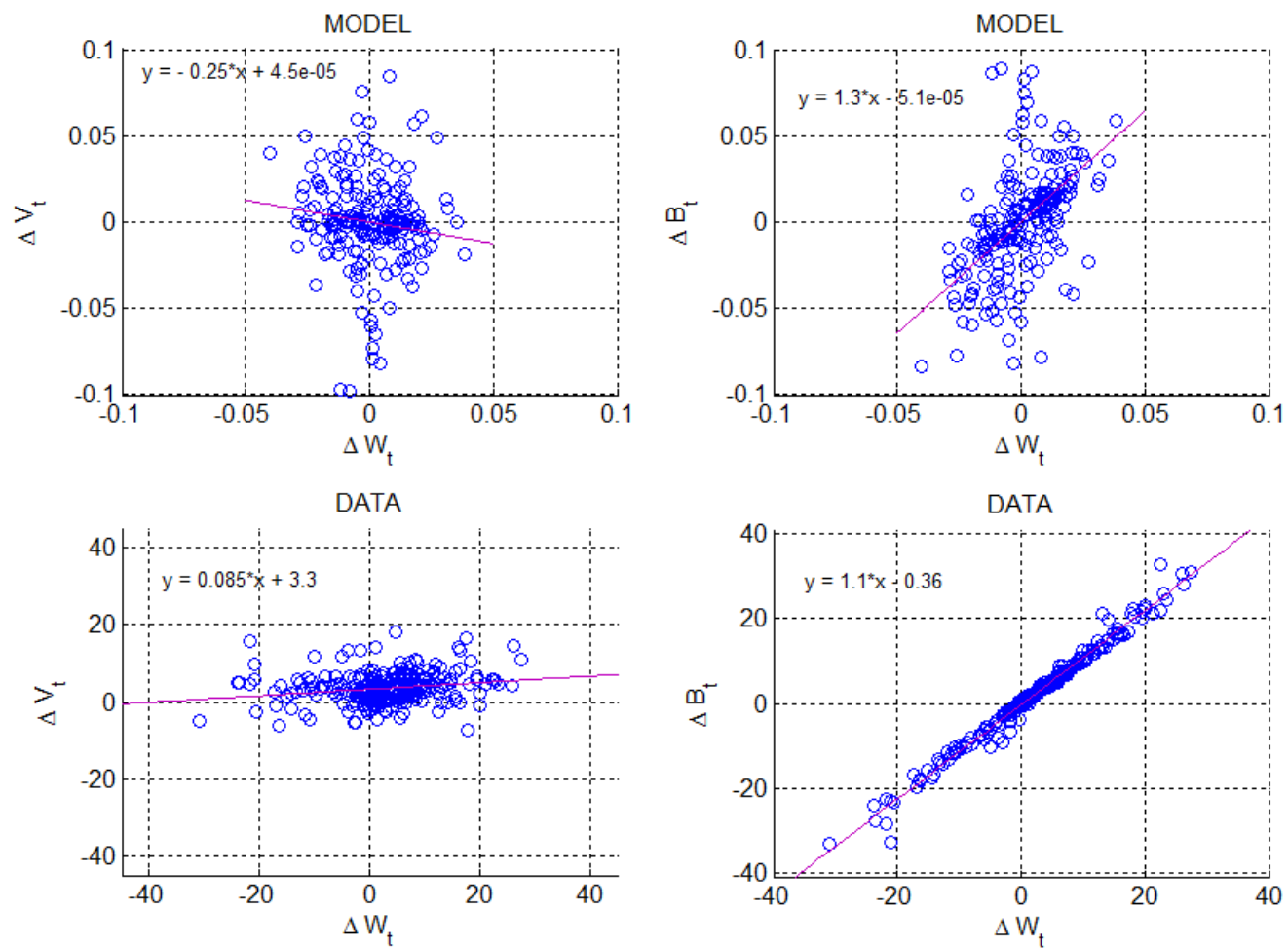

Note: The scatter plots show changes in total financial assets $(\Delta \mathrm{W})$ versus changes in equity $(\Delta \mathrm{V})$ and debt $(\Delta \mathrm{B})$ in the model and in the data for broker-dealers from financial accounts. Data sample is $1960-2014$. 
Figure 2. Correlation between Output and Leverage

\section{Baseline Simulation}
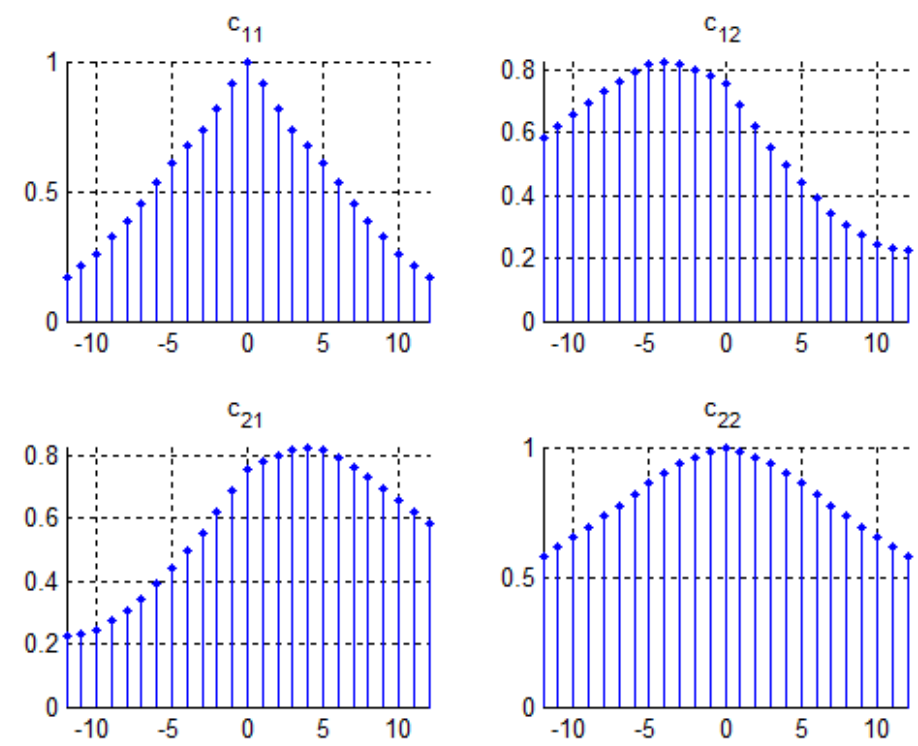

Data
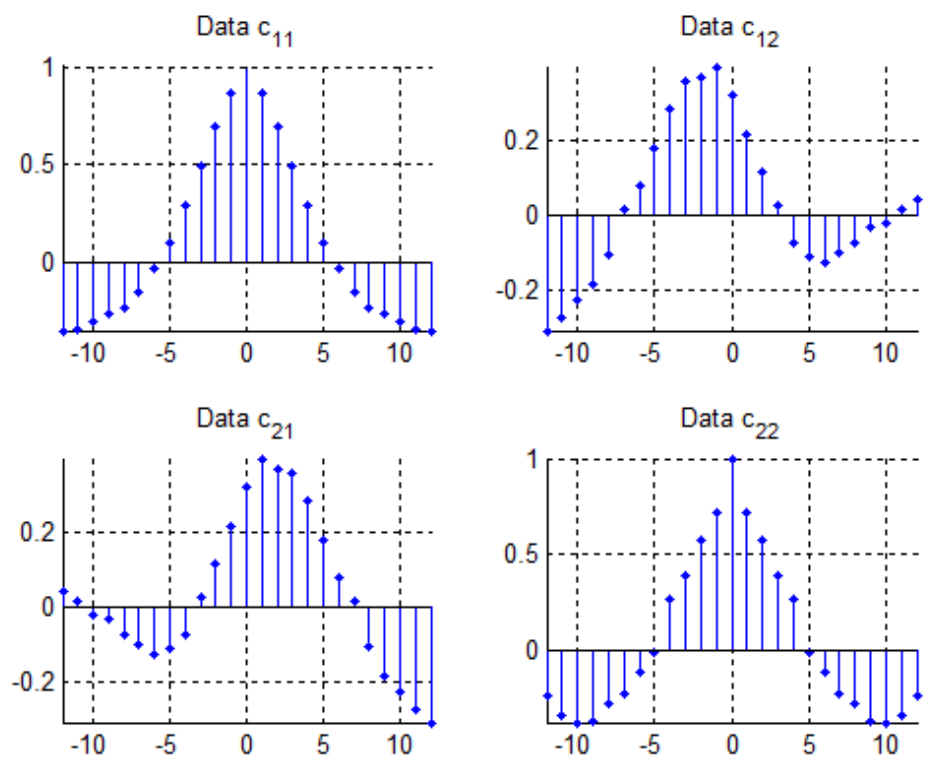

Note: Charts represent cross-correlation of de-trended output (denoted by 1) and leverage (denoted by 2) in the model and the data. C11 is the autocorrelation of output; C22 is the autocorrelation of leverage; C12 is the correlation between output and leverage. Data is HPfiltered (lambda=1600) real GDP and broker-dealer leverage 1980Q1-2014Q2. 
Figure 3. Negative Total Factor Productivity Shock
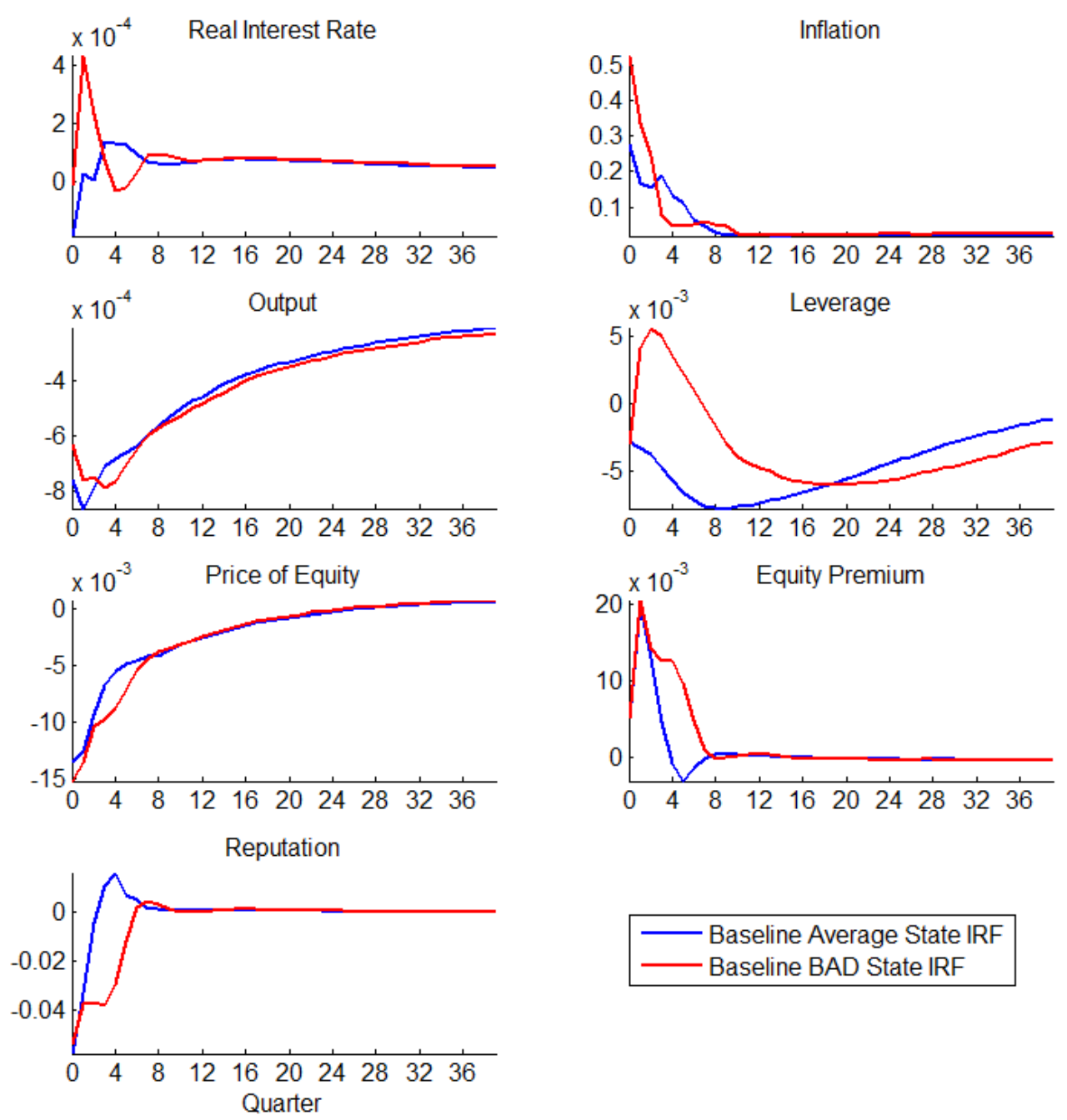

Technology Shock

Note: A bad state refers to a state with low reputation. A bad state impulse response function is defined as the mean reaction conditional to the 4-quarter average of reputation being below its $2.5^{\text {th }}$ percentile. The average state impulse response function is defined as the unconditional mean reaction. 
Figure 4a. Monetary Policy Tightening Shock
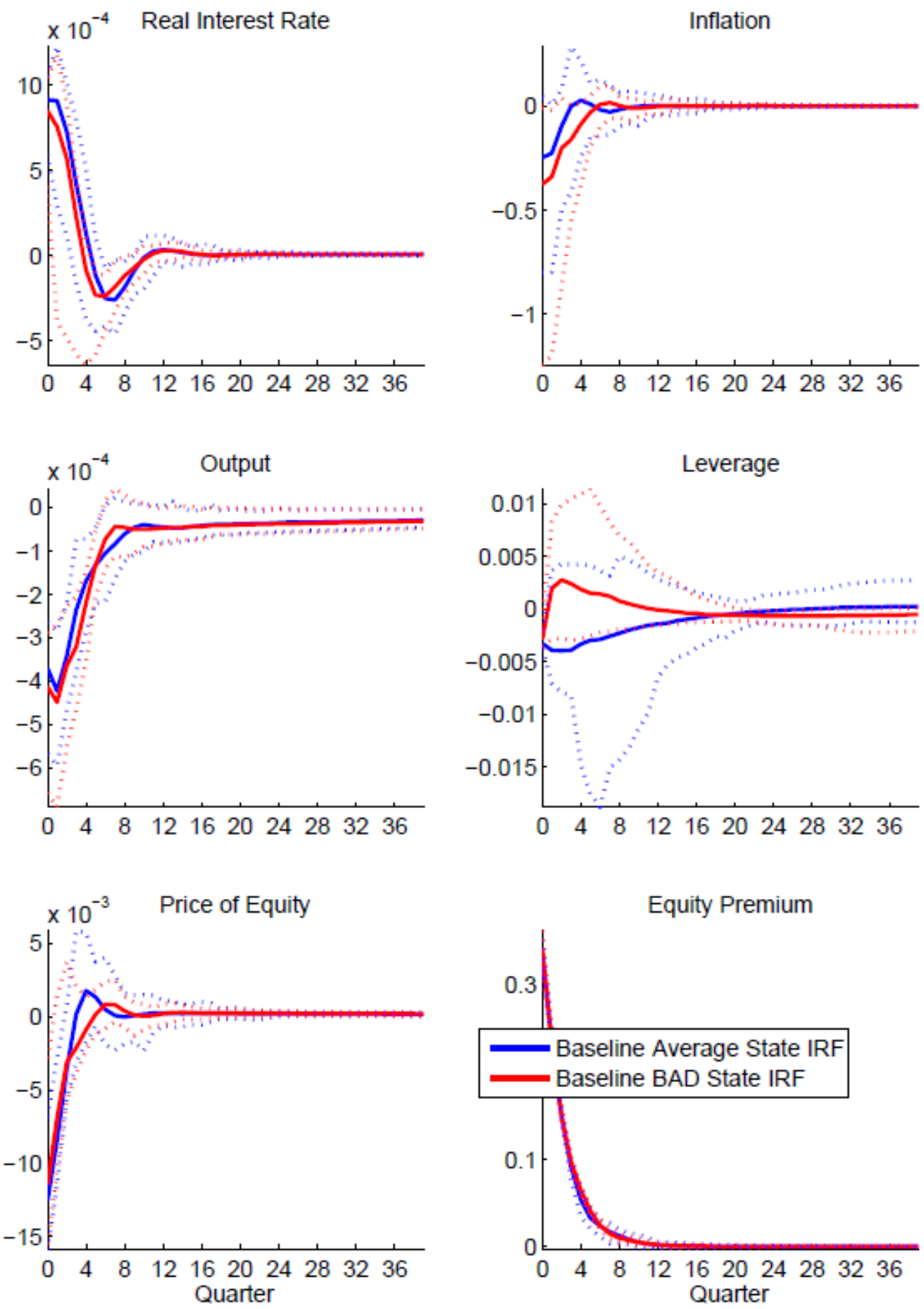

MonetaryPolicy 
Figure 4b. Monetary Policy Tightening Shock

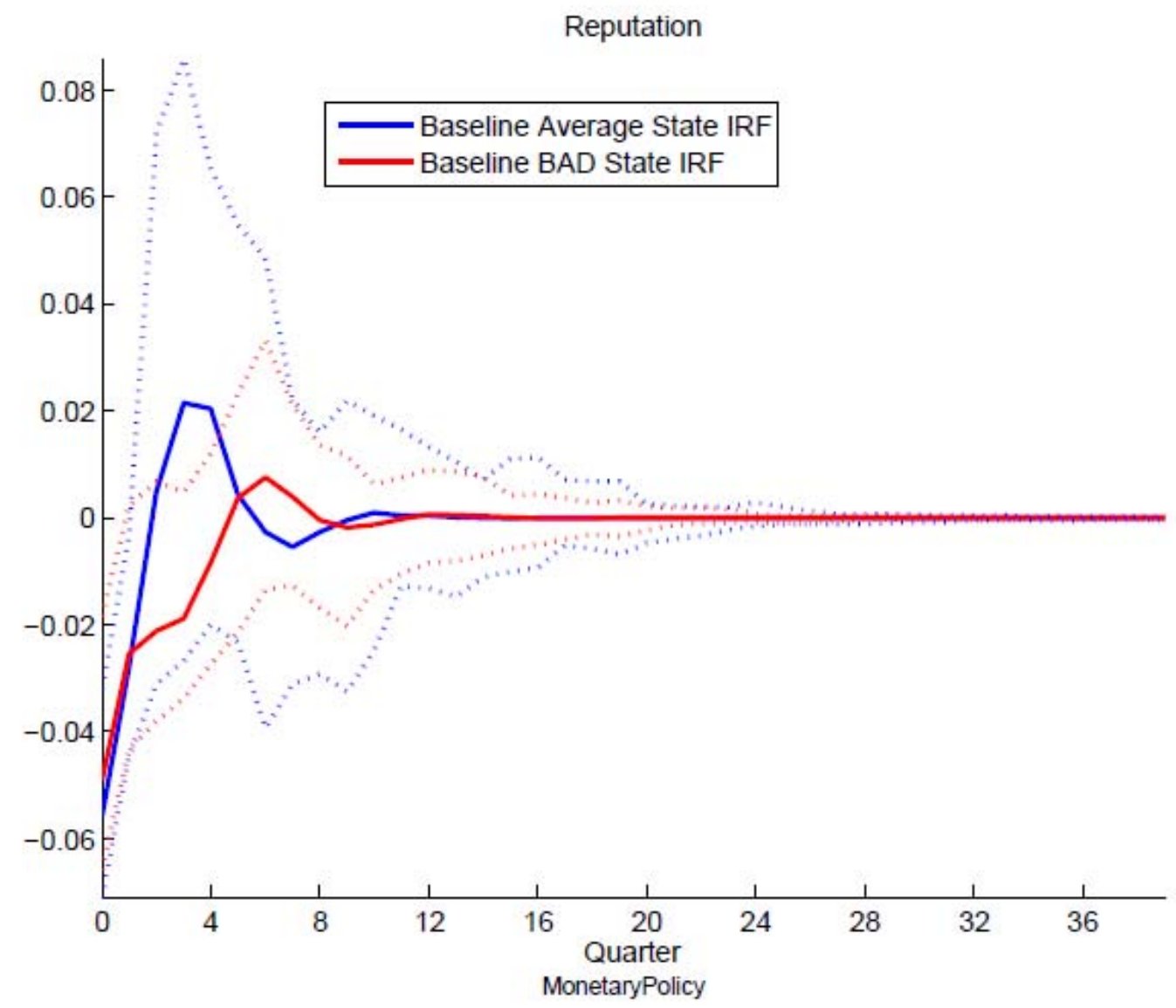

Note: Confidence bands show the uncertainty related to the combination of the monetary policy shock with demand and supply shocks and the initial state of the economy. 
Figure 5. Welfare: Baseline without Systemic Risk

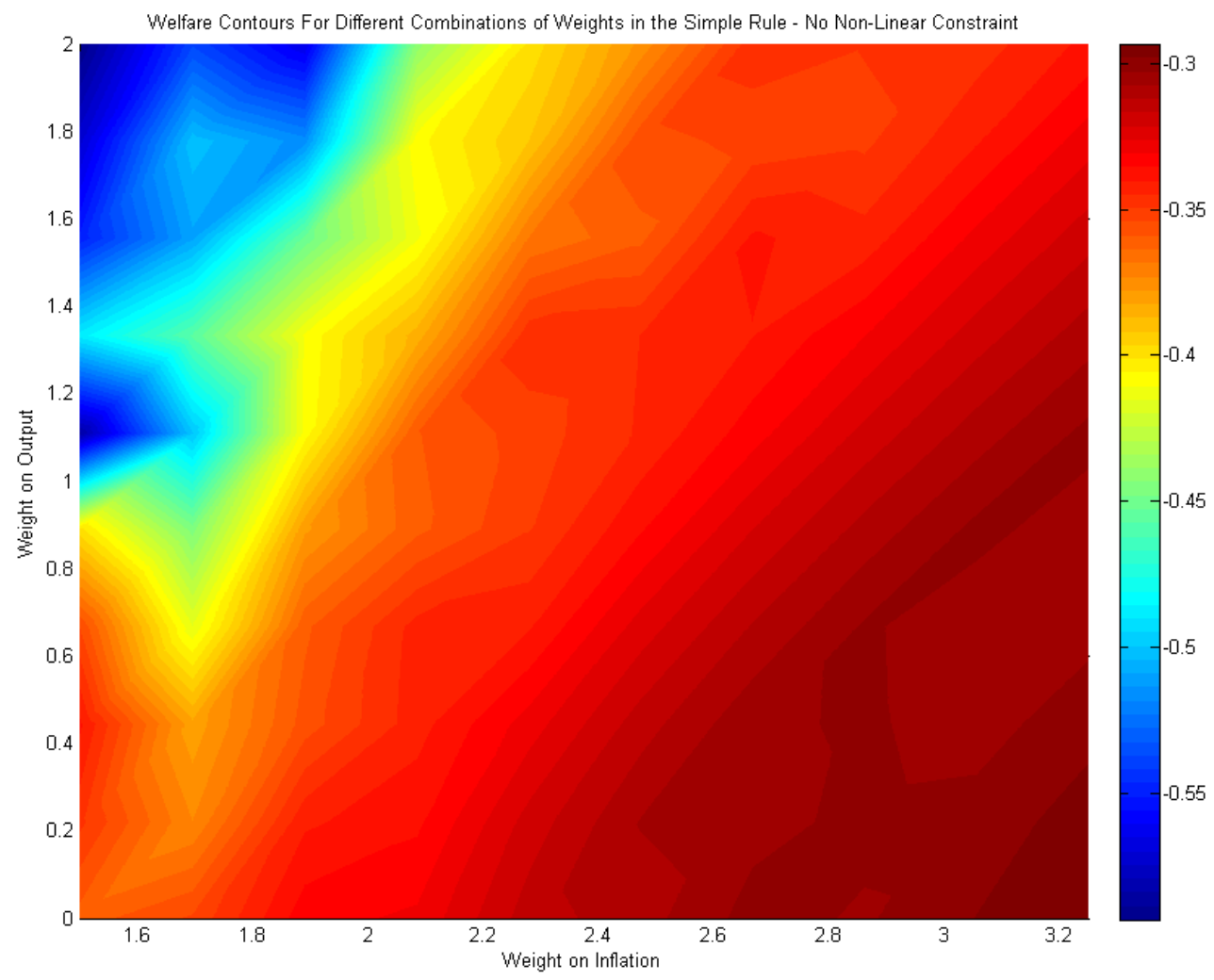

Note: Welfare is measured in terms of weighted steady state consumption equivalent. Higher (less negative) values in red indicate higher welfare. 
Figure 6. Welfare: Leverage vs. Output stabilization.

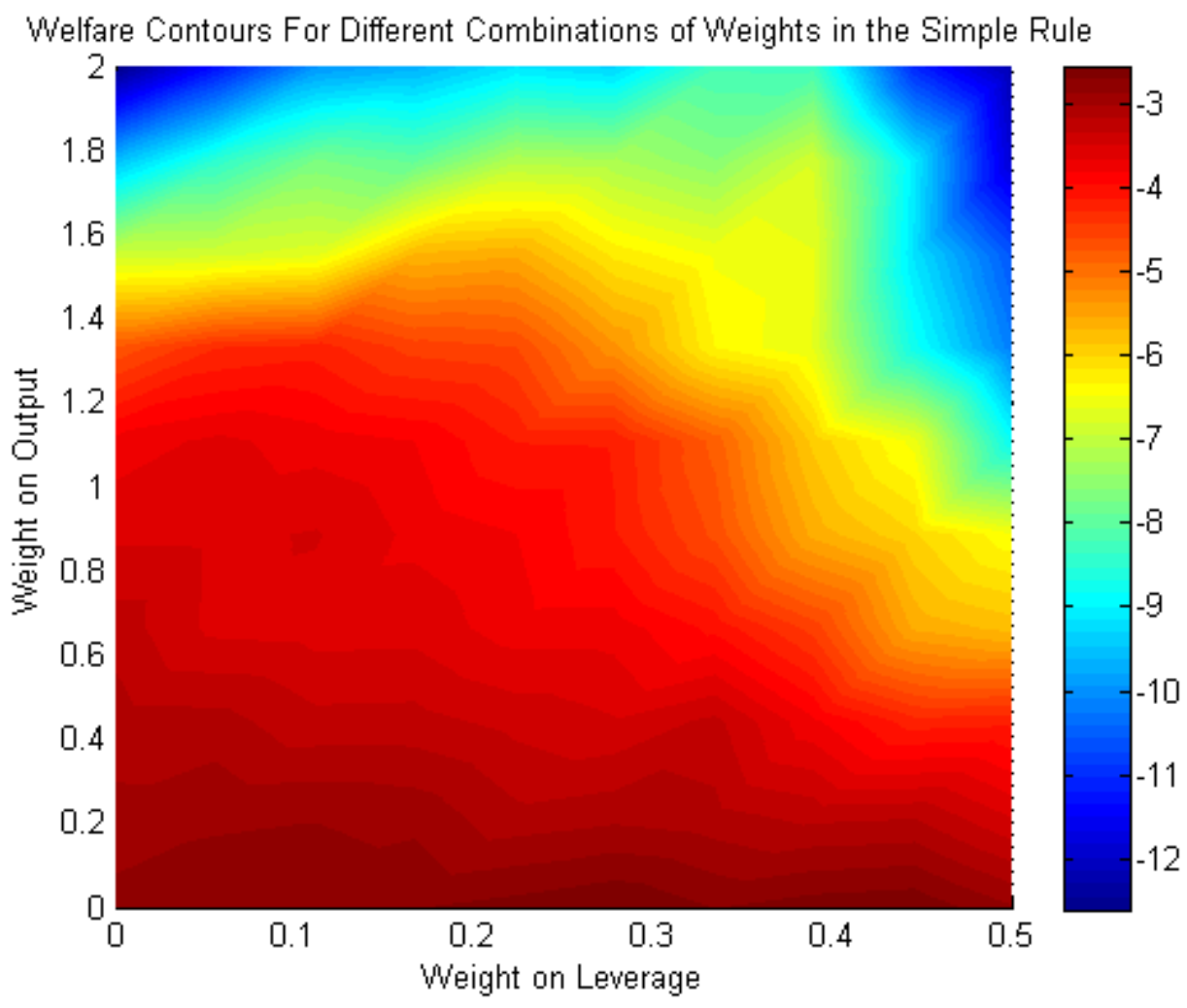

Note: Welfare is measured in terms of weighted steady state consumption equivalent. Higher (less negative) values in red indicate higher welfare. 
Figure 7. Volatility Paradox: Distribution of Output, Inflation and Leverage
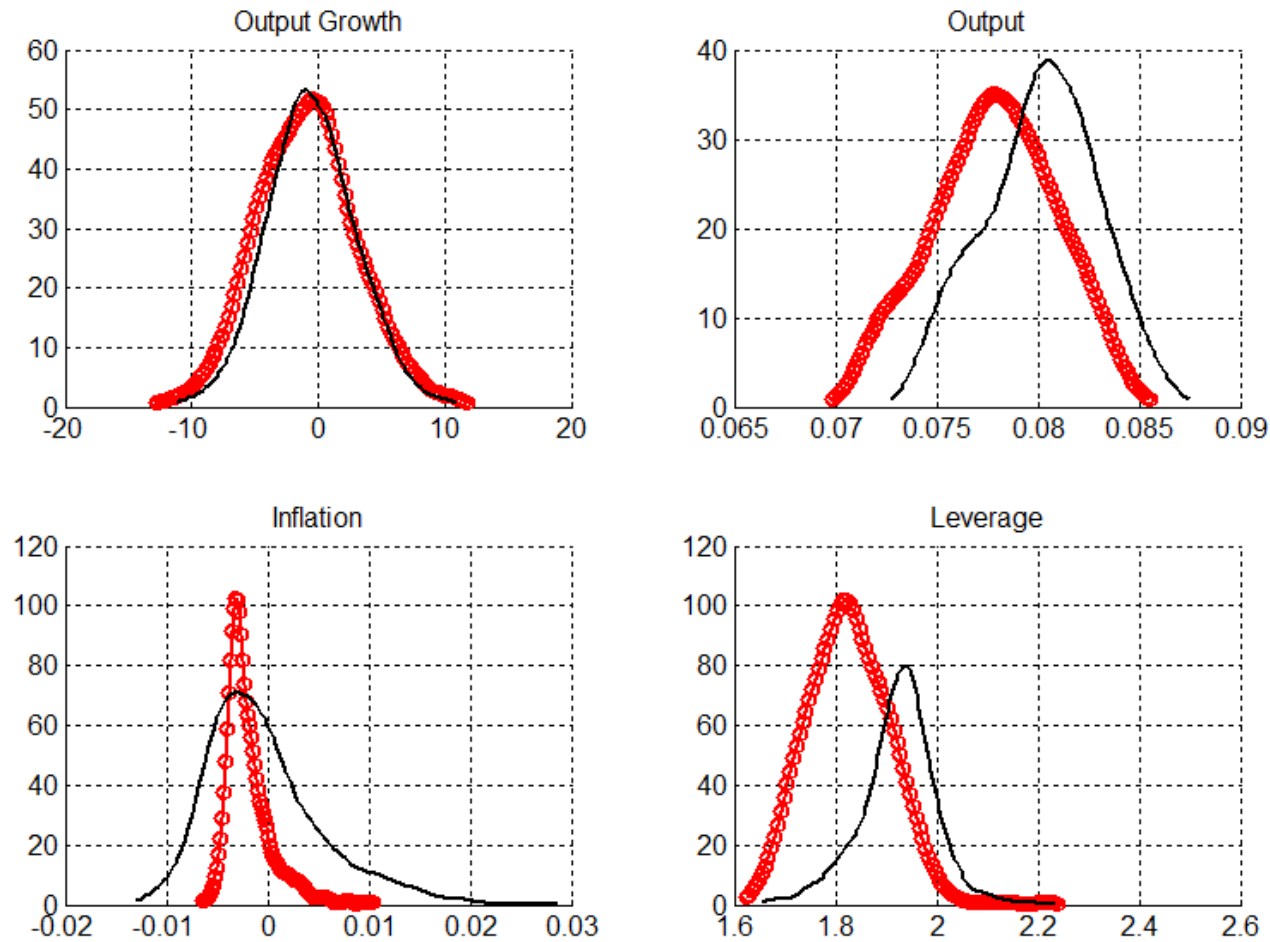

Note: Red circled distributions are under the baseline Taylor-type monetary rule where there is no reaction to output gap $\left(\phi_{x}=0\right)$. The black solid line is when the central bank reacts to output gap with a coefficient of $2\left(\phi_{x}=2\right)$. 
Figure 8. Monetary Policy Trade-Offs: Leaning against Leverage
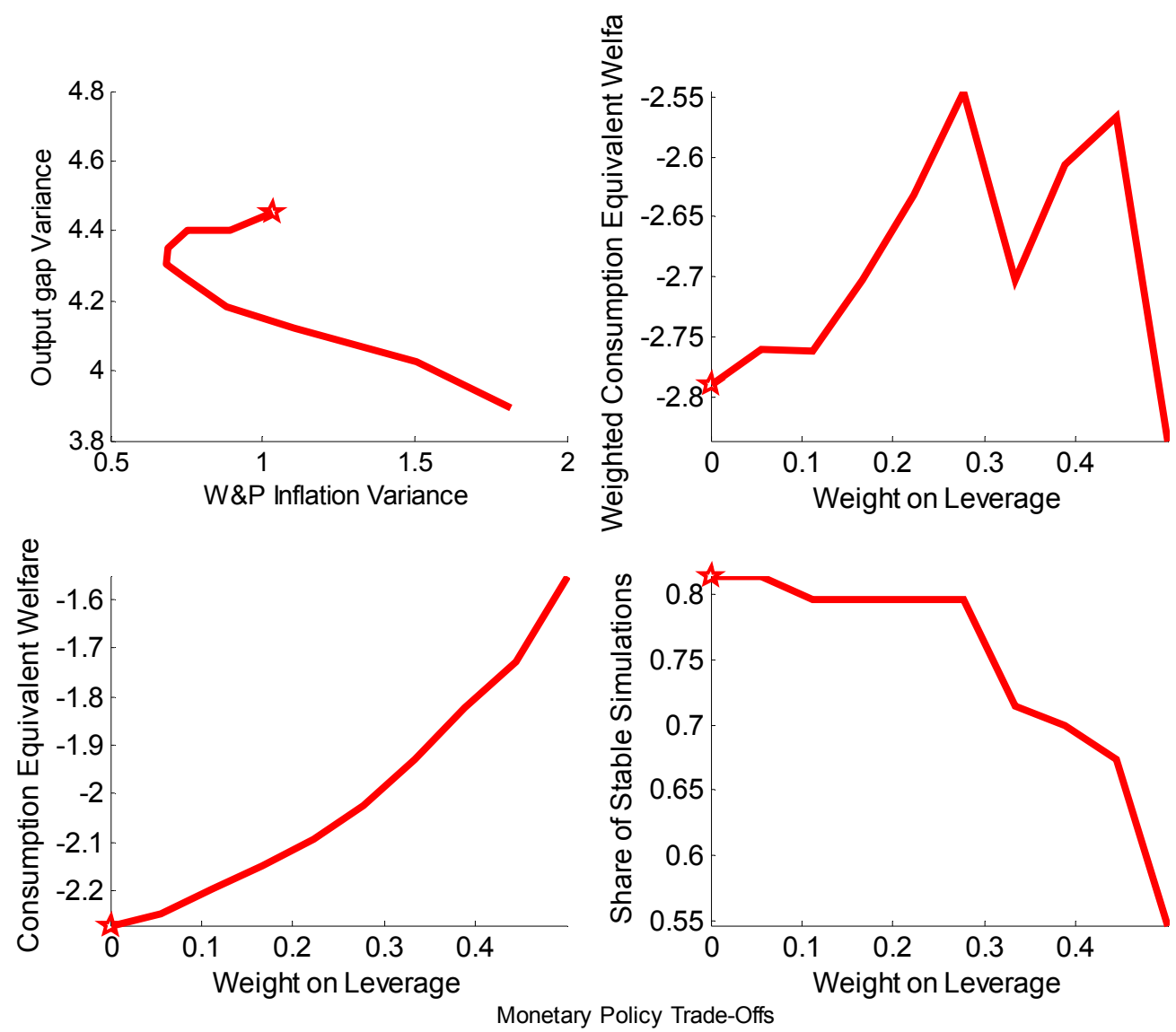

Note: Top left chart shows composite inflation and output volatility as the weight on leverage goes from 0 (indicated with a star) to 0.5. Top right chart and bottom left chart show adjusted and non-adjusted welfare as a function of the weight on leverage, respectively. Bottom right chart shows the share of stable simulations as the weight on leverage increases. 
Figure 9. Distribution of leverage

With baseline interest rate rule

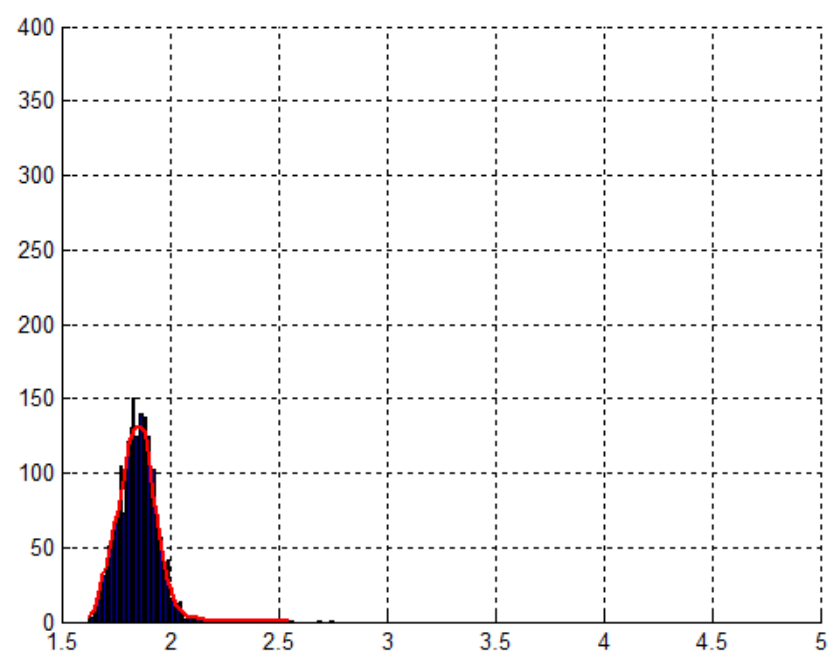

With leverage in interest rate rule

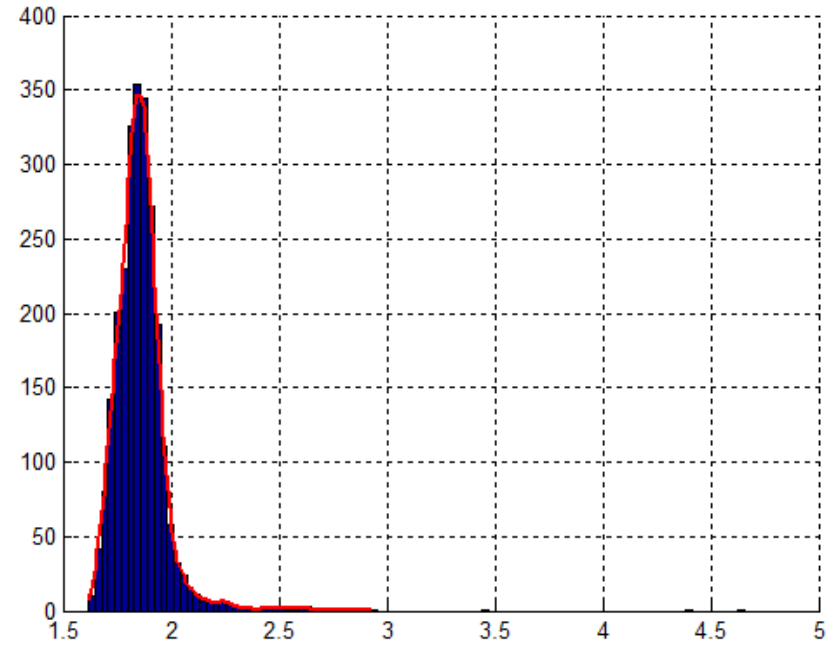

Note: Histograms of leverage for a path of the simulated economy with the baseline monetary policy rule $\left(\phi_{\theta}=0\right)$ and with a monetary policy rule with a higher weight on leverage $\left(\phi_{\theta}=0.25\right)$. 
Figure 10. Welfare: Risk Mispricing vs. Output stabilization.

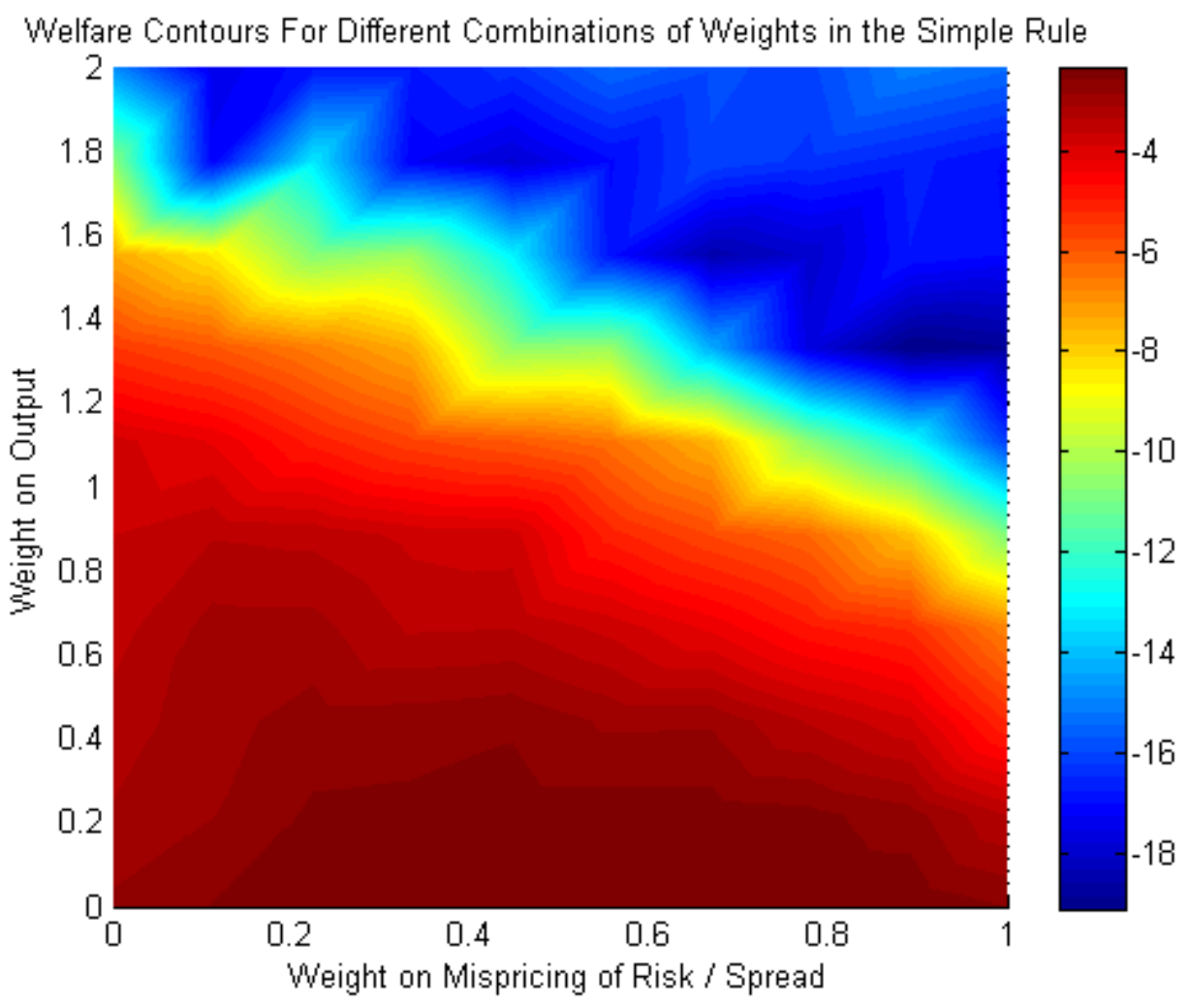

Note: Welfare is measured in terms of weighted steady state consumption equivalent. Higher (less negative) values in red indicate higher welfare. 
Figure 11. Welfare: Macroprudential vs. Interest Rates

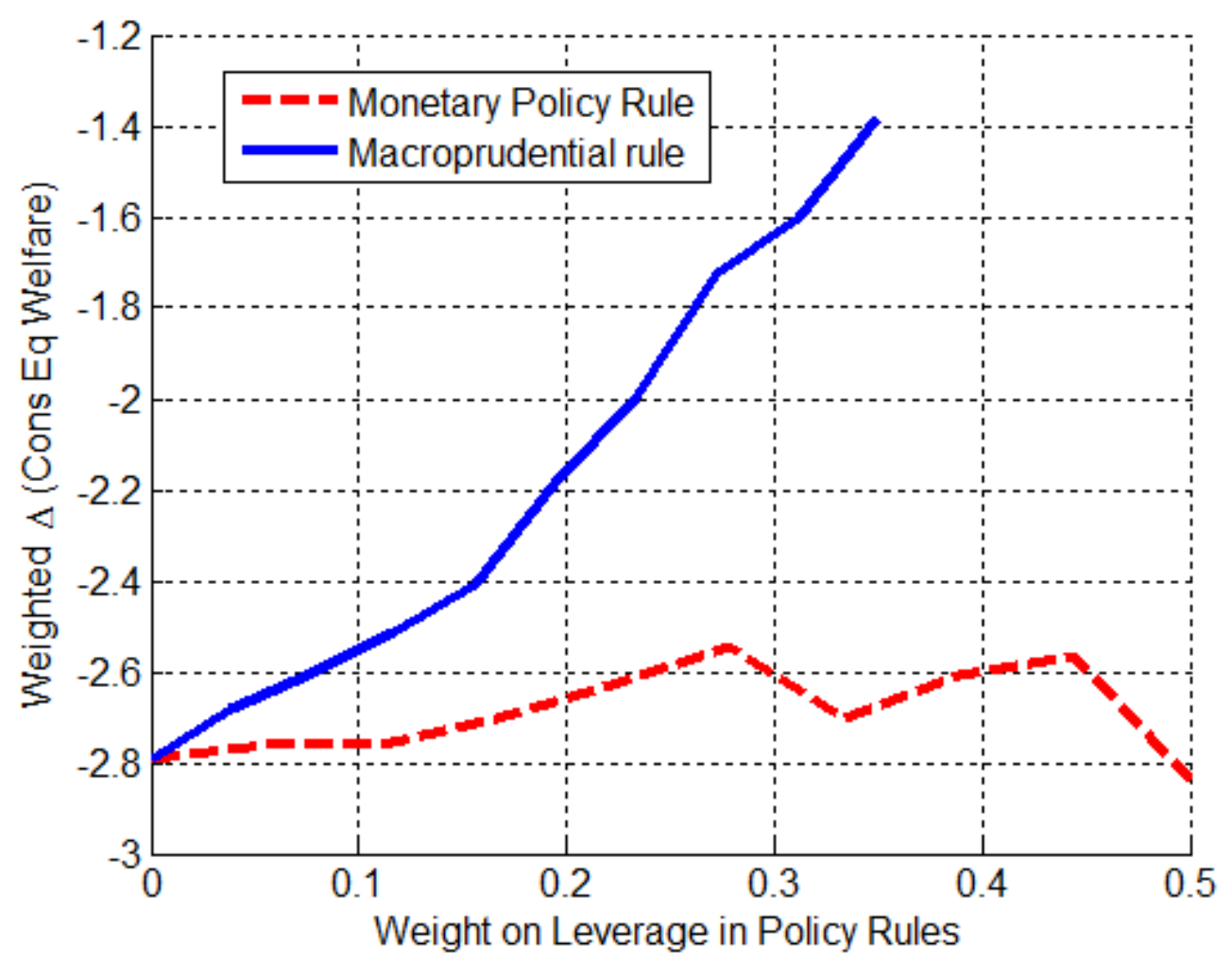

Note: $\mathrm{X}$-axis is the weight on leverage in both the macroprudential and interest rate rule. Welfare is expressed in terms of weighted steady state consumption equivalent. 